\title{
EFICIÊNCIA RELATIVA DE UNIVERSIDADES FEDERAIS BRASILEIRAS NAS ATIVIDADES DE ENSINO, PESQUISA E EXTENSÃO
}

\author{
Franciane de Oliveira Alvarenga 1 \\ Pierre Ohayon 2
}

- Artigo recebido em: 14/01/2020 -- Artigo aceito em: 30/04/2020 -." Segunda versão aceita em: 17/07/2021

\begin{abstract}
RESUMO
Objetivou-se avaliar o nível de eficiência relativa de Universidades Federais Brasileiras nas atividades de ensino, pesquisa e extensão, uma vez que elas impulsionam o crescimento socioeconômico, fazendo-se necessário que os gastos públicos sejam feitos de forma eficiente, atentando-se à produtividade. Para isso, utilizou-se a técnica Análise por Envoltória de Dados. A pesquisa é caracterizada como descritiva e de abordagem quantitativa, sendo composta por 34 universidades federais brasileiras, adotando-se uma análise longitudinal entre os anos de 2013 e 2017. Para as atividades de ensino, observou-se que nove universidades apresentaram eficiência total ao longo do período analisado, sendo que 2014 foi o ano que apresentou os piores níveis de eficiência e 2016 o melhor. Já para as atividades de pesquisa, os resultados apontaram que nove universidades foram $100 \%$ eficientes ao longo do período de análise, apontando que 2014 foi o pior ano (com menores níveis de eficiência) e 2017 o melhor. Por fim, em relação às atividades de extensão, os resultados mostram que as universidades têm mais dificuldades para se manterem totalmente eficientes, visto que apenas três universidades são consideradas $100 \%$ eficientes em relação ao grupo de análise nos anos compreendidos, apontando que 2014 foi o ano que as universidades tiveram melhores níveis de eficiência e 2017 o pior ano. Sabendo que a missão das universidades é realizar atividades de ensino, pesquisa e extensão, observou-se que apenas a Universidade Federal de Minas Gerais e a Universidade Federal de Ciências da Saúde de Porto Alegre se mantiveram 100\% eficientes em todas as atividades em conjunto e nos anos analisados.
\end{abstract}

Palavras-Chave: Análise por Envoltória de Dados. Universidades Federais. Ensino, Pesquisa e Extensão. Eficiência Relativa.

\footnotetext{
1 Doutora em Ciências Contábeis pela Universidade Federal do Rio de Janeiro - UFRJ, Professora na Universidade Federal de São João del-Rei - UFSJ. Endereço: Av. Prefeito Lourival Gonçalves de Andrade, 1407, Vila Belizário, São João del-Rei- MG, Brasil, CEP 36.307-161. Telefone: (32)98840-0090. E-mail: francianealvarenga@ufsj.edu.br http://orcid.org/0000-0002-4008-1429

2 Doutor em Administração pela Universidade de São Paulo - USP, Professor na Universidade Federal do Rio de Janeiro - UFRJ. Endereço: Av. Borges de Medeiros, 3535 apto 902, Lagoa, Rio de Janeiro-RJ, Brasil, CEP 22.470-00. Telefone: (21)99919-8025. E-mail: pohayon@facc.ufrj.br https://orcid.org/0000-0002-2209-0006
}

Editor responsável pela aprovação do artigo: Dr. Ewerton Alex Avelar Editora responsável pela edição do artigo: Drª . Bruna Camargos Avelino 


\title{
RELATIVE EFFICIENCY OF BRAZILIAN FEDERAL UNIVERSITIES IN TEACHING, RESEARCH AND EXTENSION ACTIVITIES
}

\begin{abstract}
This study aimed to evaluate Brazilian Federal Universities' relative efficiency in teaching, research, and extension activities. Evaluations of efficiency and productivity are crucial since these activities promote socio-economic growth and are funded with public resources. This descriptive, longitudinal, and quantitative research adopted data envelopment analysis to examine 34 Brazilian federal universities between 2013 and 2017. The results showed that 2014 was the worst, and 2016 was the best year regarding efficiency levels for teaching activities, and nine universities were $100 \%$ efficient in these activities in the period examined. As for research activities, the results showed that nine universities were $100 \%$ efficient in the period; 2014 was the year with the lowest levels of efficiency, and 2017 the year with the best. Finally, results for extension activities show that universities have more difficulties to be fully efficient. Only three universities were considered $100 \%$ efficient, with 2014 as the year that universities had the best efficiency levels and 2017 the worst year. Only the Federal University of Minas Gerais and the Federal University of Health Sciences of Porto Alegre perfectly fulfilled their mission by showing total efficiency in all teaching, research, and extension activities during the period studied.
\end{abstract}

Keywords: Data Envelopment Analysis. Federal Universities. Teaching, Research, and Extension. Relative efficiency.

\section{INTRODUÇÃO}

Analisar a eficiência das organizações afeta diretamente a sua gestão e o processo decisório advindos de seus gestores. A partir de análises sobre variáveis de natureza financeira e não financeira é possível definir o nível de eficiência ou de ineficiência e verificar as razões que conduziram a esses resultados, buscando assim a otimização. Além disso, Dufrechou (2016) menciona que as instituições públicas mais eficientes aliviam as restrições orçamentárias, alcançando os mesmos resultados com menos recursos ou melhorando os resultados dos investimentos atuais.

Apesar das várias obrigações sociais do Governo, a educação é uma das políticas sociais mais eficientes para que haja desenvolvimento social, econômico e ambiental. Sonje et al. (2018) defendem que os investimentos na educação é uma importante fonte de formação de capital humano e crescimento econômico. Ademais, consideram-se os gastos públicos de extrema importância para a economia, pois estes geram externalidades positivas - como aumento de produtividade, geração de empregos e inovação tecnológica -, sobretudo, no que tange à provisão dos serviços de educação e saúde (Cândido Junior, 2001).

A busca por eficiência teve início em 1980, que com a escassez de recursos e o aumento da demanda por políticas sociais, o Estado precisou realizar os seus gastos de forma mais eficiente. Foi então que, em 1995, deu-se início à chamada Reforma Gerencial, que buscava maior eficiência, eficácia e transparência na aplicação dos recursos públicos. A partir disso, estudos sobre a correta alocação 
dos recursos públicos e o desenvolvimento econômico e social da sociedade têm se destacado (Bresser-Pereira, 1999; Marini \& Martins, 2004; Petrucci \& Schwarz, 1999).

Para Martos (2013), a eficiência pressupõe a elaboração do orçamento na justa medida de identificar se as necessidades públicas foram alcançadas de forma eficiente. Isto é, identificar se a arrecadação, bem como o gasto, foram otimizados a fim de atender aos fins sociais da forma mais racional possível. Arretche (1999, p. 35) também entende que a eficiência é a mais urgente e necessária no âmbito da administração pública porque "a escassez de recursos públicos exige maior racionalização do gasto". Assim, o sucesso da atividade financeira em relação ao gasto se dá ao se realizar a atividade com igualdade e efetivo atendimento das necessidades públicas, observando os direitos e garantias fundamentais da sociedade.

Em se tratando de educação, ações e políticas públicas específicas são definidas, implantadas e implementadas, entre outros órgãos, pelas Instituições Federais de Ensino Superior (IFES), dentre elas as Universidades Federais (UFs). Essas entidades públicas são fundamentais para a sociedade uma vez que contribuem para o desenvolvimento social e econômico do País, ao trazerem benefícios de natureza social, cultural, econômica, educativa, tecnológica e moral, por meio da produção e transmissão do conhecimento.

Sabendo que as IFES são organizações públicas e que não objetivam lucro, fazendo com que avaliações baseadas em preços, custos e investimentos sejam substituídas por outros enfoques que considerem múltiplos recursos e múltiplos resultados que não podem ser reduzidos a uma unidade comum de medida (Ahn, 1987). Assim, por meio dos recursos, estas visam proporcionar à sociedade um ensino de qualidade, realizar pesquisas, aperfeiçoar e gerar novos conhecimentos, além de buscarem se inserir no meio social por meio de atividades de extensão, com o objetivo de contribuir para o desenvolvimento da população local.

As ações de ensino, pesquisa e extensão praticadas pelas instituições de ensino obedecem ao princípio da indissociabilidade, instituído na Carta Magna de 1988, em seu artigo 207 (Brasil, 1988). Desse modo, pode-se entender o ensino, pesquisa e extensão como funções pelas quais a missão das universidades se realiza, quais sejam, "formar ou ensinar, investigar ou pesquisar e servir ou exercer a atividade de extensão" (Ospina, 1990, p. 138).

Esse tripé de ações - ensino, pesquisa e extensão - reflete o perfil peculiar que a execução do orçamento das IFEs apresenta, contribuindo para a formação dos cidadãos e, consequentemente, para o incremento do capital humano ao favorecer a redução das assimetrias na qualidade de vida da população brasileira.

Castano \& Cabanda (2007) mencionam que, ao medir a eficiência, é possível avaliar o desempenho de uma organização, comparando-a a uma contraparte privada e a padrões de melhores práticas internacionais. Assim, percebe-se a importância de conhecer como está a gestão das UFs, avaliando sua eficiência relativa de modo a verificar se elas têm cumprido o papel social que lhes é atribuído. 
Diante da importância e representatividade das UFs no cenário nacional, este trabalho tem como objetivo avaliar o nível de eficiência relativa de Universidades Federais brasileiras nas atividades de ensino, pesquisa e extensão. Uma vez que, percebe-se que os gestores precisam trabalhar de modo eficiente, fazendo com que a redução de recursos aplicados às UFs não cause desmotivação e nem traga implicações nos resultados das instituições.

Espera-se que este estudo possa contribuir de forma prática e metodológica no campo das finanças públicas de maneira a possibilitar o aperfeiçoamento na condução da aplicação dos recursos públicos por parte dos gestores das UFs. Em especial, o estudo volta-se para a análise e discussão da relação entre eficiência da gestão no que tange à aplicação dos recursos públicos e ao desempenho das funções das UFs, expressas no tripé ensino, pesquisa e extensão.

Além disso, trata-se de uma investigação relevante por se propor a aplicar a metodologia da Análise por Envoltória de Dados (DEA) para avaliar as atividades de ensino, pesquisa e extensão separadamente às universidades, buscando verificar isoladamente em quais atividades o quão são eficientes em sua gestão e se há indissociabilidade do tripé ensino-pesquisa-extensão, além de atender satisfatoriamente às necessidades da sociedade.

De acordo com a legislação vigente, o tripé formado pelo ensino, pesquisa e extensão constitui o eixo fundamental da universidade brasileira e não pode ser compartimentado. Além disso, o Decreto 3.860/2001 disciplina que as IFES se caracterizam pela oferta regular de atividades de ensino, de pesquisa e de extensão, obedecendo ao princípio de indissociabilidade das atividades (Brasil, 2001).

Santos (2004, p. 31), por sua vez, menciona que esse tripé funciona como um catalisador do conhecimento "pluriversitário", que permite "a inserção da universidade na sociedade e a inserção desta na universidade". Castro (2004) também defende esse posicionamento ao afirmar que a história da indissociabilidade ensino-pesquisa-extensão tem como pano de das relações entre conhecimento científico e demandas sociais.

Dessa forma, o ensino universitário engloba não só a transmissão do conhecimento em sala de aula, mas a pesquisa, que pode ser pura ou aplicada, e a objetivação desta, por meio da extensão. Assim, esses três eixos configuram os pilares ou os valores essenciais para que a universidade, como agente de transformação e transmutação, seja preservada.

Pivetta et al. (2010) destacam a importância dos três pilares e da relação existente entre eles, mencionando que são atividades complementares e interdependentes; além disso, precisam ter as mesmas valorações no sistema universitário, sob o risco de desenvolver conhecimento deficiente e reducionista. Esse tripé é, portanto, fundamental para a qualidade e o sucesso dos profissionais formados pelas universidades, e depende, em grande parte, do nível de interação e articulação entre os três pilares do conhecimento uno e multidimensional. Sendo difícil, portanto, conceber um aluno universitário bemsucedido sem a influência de uma formação sistêmica, ampliada e integrada, proporcionada pelo ensino, pesquisa e extensão. 
Estudos similares como o Corbucci (2000), Belloni (2000), Oliveira \& Turrioni (2006), Costa et al. (2010), Nuintin (2014), Curi (2015), Gomes (2016) e Moreira (2018) também utilizaram a metodologia DEA para avaliar a eficiência das UFs e serviram como base de pesquisas. Entretanto, nenhum desses autores estudou a eficiência da gestão em relação ao papel social que the é atribuído, ou seja, atender à missão que the cabe, desenvolver ações de ensino, pesquisa e extensão, o que este estudo pretende fazer.

\section{REFERENCIAL TEÓRICO}

\subsection{Eficiência nas Universidades Federais}

A realização da avaliação da eficiência em âmbito público é fundamental e deve ser adotada pelos gestores públicos, tendo em vista que os reflexos dos investimentos realizados nos diversos setores devem ser transformados em serviços de qualidade e no crescimento dos indicadores sociais da população.

A essência do conceito de eficiência no setor público é a mesma que no privado. Para que uma ação seja eficiente, espera-se que as ações a serem desenvolvidas pelo ente público absorvam menos recursos públicos ou otimizem os recursos existentes de três formas, conforme apresentado por Gomes (2010): gastar apenas o que é necessário; utilizar equipamentos e recursos eficientes; e, combater o desperdício e aperfeiçoar o uso dos recursos.

O princípio da eficiência foi introduzido expressamente no caput do art. 37 da Constituição Federal (CF), por meio da Emenda Constitucional n. 19/1998, que dispôs sobre os princípios e as normas da administração pública, com vistas a impor o controle das finanças e direcionar a busca da eficiência gerencial de uma gestão pública eficaz (Brasil, 1988).

Fuentes et al. (2016) mencionam que a eficiência do ensino superior universitário é crucial para o desenvolvimento e crescimento dos países. Especificamente, a produção de capital humano e a criação de novos conhecimentos são fatores fundamentais para as economias nacionais que devem competir em nível internacional.

Para Baracho (2000), a análise da eficiência no setor público compreende os seguintes aspectos: (i) comparação do serviço prestado ou bem adquirido ou vendido, em relação com seu custo; (ii) comparação do rendimento com uma referência ou padrão previamente estabelecido; (iii) recomendações para melhorar os rendimentos apurados e a crítica dos resultados obtidos.

Tavares et al. (2011) ressaltam que, no Brasil, a avaliação da educação superior vem tomando força e ganhando foco nos planos governamentais frente à integração do País ao cenário mundial. Isso se deve à nova concepção do poder e papel do Estado nos padrões do modelo de globalização como opção diante da crise de acumulação de capital. Os autores afirmam que essa relação configura um Estado mínimo com suas organizações política, jurídica e ideológica no campo dos direitos sociais, tais como a educação.

Meyer Júnior (1993) complementa que a avaliação é um importante e necessário instrumento de gestão nas Universidades, pois possibilita medir seus esforços, sua qualidade, excelência, utilidade e relevância, a fim de implementar novos procedimentos e estratégias. 
Lapa \& Neiva (1996) classificam os critérios mais usuais de avaliação das UFs em dois grandes grupos: os ligados à ideia de desempenho (aí considerados, produtividade, eficiência, eficácia e efetividade) e aqueles ligados à ideia de qualidade (utilidade e relevância).

Corbucci (2007) corrobora afirmando que para avaliar a qualidade e a eficiência do ensino superior existe uma certa complexidade. Apesar de alguns autores utilizarem indicadores de desempenho em seus estudos, ainda que indiretamente, eles procuram se aproximar do que seria ensino de qualidade. Esta abordagem tem como vantagem a possibilidade de que o desempenho entre instituições seja comparado.

Consoante a isso, Lapa \& Neiva (1996) destacam que a qualidade é considerada sob o ponto de vista da utilidade ou da relevância, sendo que os julgamentos de qualidade estão ligados a visões "políticas" de valor.

Assim, Dufrechou (2016), as instituições públicas mais eficientes aliviam as restrições orçamentárias, alcançando os mesmos resultados com menos recursos ou melhorando os resultados dos investimentos atuais.

No Brasil, as IFES são avaliadas pelo TCU, ao qual cabe auxiliar no controle externo da fiscalização contábil, financeira e orçamentária da União. Cruz (2004) observa que o TCU realiza auditorias de natureza contábil, financeira, orçamentária, operacional e patrimonial, permitindo avaliar o desempenho nas diversas modalidades. O TCU também fiscaliza a correção na utilização dos recursos públicos, avaliar aspectos gerenciais, como a eficiência, a eficácia, a efetividade e a economicidade no uso dos recursos envolvidos.

Para Oliveira \& Turrioni (2006), as avaliações das IFES pelo TCU ainda não retratam de forma clara o desempenho e necessidades reais das instituições, mas, atualmente, ainda são as melhores ferramentas para análise do desempenho e da eficiência.

O TCU utiliza nove indicadores para avaliar as IFES (TCU, 2006), esses indicadores integram o relatório de gestão das IFES por força da Decisão $N^{\circ}$ 408/2002/TCU. São eles: Custo Corrente/Aluno Equivalente; Aluno Tempo Integral/ Professor Equivalente, Aluno Tempo Integral/ Funcionário Equivalente, Funcionário Equivalente / Professor Equivalente, Grau de Participação Estudantil, Grau de Envolvimento Discente com Pós-Graduação, Conceito CAPES/MEC para a PósGraduação, Índice de Qualificação do Corpo Docente e Taxa de Sucesso na Graduação (TCU, 2006, p. 4).

O TCU (2006), ao instituir esses indicadores para serem calculados e demonstrados pelas IFES em seus relatórios de gestão anual, tende a atender a três requisitos essenciais: ser operacionalmente passíveis de apuração, possuir atributo de comparabilidade e apresentar a capacidade de representar confiavelmente aspectos da realidade acadêmica.

Dessa forma, os relatórios institucionais permitem que o TCU acompanhe a gestão, eficiência e resultados advindos das universidades, favorecendo a criação de políticas públicas, bem como a alocação de recursos públicos, impactando assim a educação e consequentemente o desenvolvimento social. 


\subsection{Análise por Envoltória de Dados - DEA}

A DEA é uma técnica baseado em programação linear para calcular a eficiência relativa das unidades e foi introduzido por Charnes et al. (1978), fundamentados nos estudos de Koopmans (1951), Debreu (1951) e Farrell (1957). O surgimento do termo e a popularização do uso da programação linear para delineamento e comparação de eficiências, foi apresentado pelos autores no trabalho "Measuring the efficiency of decision making units", publicado no ano de 1978, no European Journal of Operational Research (Daraio \& Simar, 2007; Ferreira \& Gomes, 2012, Lins \& Meza, 2000).

Essa técnica objetiva avaliar a eficiência relativa, isto é, em termos comparativos aos melhores padrões de excelência (benchmarks), de uma amostra de organizações produtivas que tomam decisões, também chamadas de Decision Marking Units (DMU). Podem ser exemplos de DMUs: empresas privadas, instituições públicas, financeiras, sem fins lucrativos, departamentos ou setores internos, dentre outras. Devido à sua flexibilidade no processo de avaliação, a DEA tem uma vasta base de utilização prática em diferentes segmentos. Revilla et al. (2003) e Hsu \& Hsueh (2009) destacam sua utilização em programas governamentais.

Dessa forma, a DEA assume uma característica importante, que é a técnica que permite uma comparação do desempenho de uma DMU objetivo com as outras DMU's. Sendo assim, a técnica mede a eficiência relativa, não absoluta, das entidades, com o intuito de ter uma visão de melhorar o desempenho.

Kozyreff Filho e Milioni (2004) também afirmam que o objetivo da DEA consiste em comparar certo número de DMUs, que realizam tarefas similares e se diferenciam nas quantidades de inputs que consomem e de outputs que produzem. Determinada a eficiência do conjunto, as DMUs mais eficientes podem balizar as ineficientes, sendo utilizadas como referência no estabelecimento de metas com a função de melhorar o desempenho, sendo esta eficiência chamada de eficiência relativa.

Assim, a análise DEA mede a eficiência relativa de cada unidade com respeito aos melhores desempenhos observados, ou seja, a eficiência será específica de acordo com as variáveis consideradas no estudo e ainda o grupo em que a unidade tomadora de decisão está inserida. Os melhores desempenhos determinam fronteiras de produção constituindo limites aos resultados alcançáveis com um dado conjunto de recursos. Assim, os índices de eficiência de uma unidade são medidos a partir das posições relativas por ela ocupados em relação àquelas fronteiras. Com isso, interpreta-se cada resultado como descritivo das habilidades e das restrições objetivas que o determinam, admitindo-se que, contornadas as restrições e ampliadas as habilidades, os resultados possam ser incrementados (Lapa et al., 1997).

Avkiran (2001) ainda menciona que isso possibilita aos gestores de políticas públicas e dirigentes das universidades alocar melhor os recursos disponíveis no sentido de aprimorar a produtividade do setor público.

Segundo Wen-Chih et al. (2012), a DEA permite otimizar individualmente cada uma das observações, uma em relação às demais, formando assim uma fronteira de eficiência. Essa fronteira de eficiência é definida segundo o conceito de Pareto-Koopmans, pelo nível máximo de produção para um dado nível de 
insumo. As unidades da fronteira são classificadas como eficientes e as outras como ineficientes. O índice de eficiência é calculado em função da forma de projeção das ineficiências na fronteira. Nos modelos clássicos, duas formas de projeção são utilizadas: modelos orientados para a redução de input (que calculam a máxima redução de input para uma mesma produção de output) e os modelos orientados para a expansão de output (que calculam a máxima expansão do output, dada certa utilização de input).

Assim, de acordo com Colin (2007), a DEA permite (1) a identificação das DMUs mais eficientes, (2) a distinção das DMUs menos eficientes comparadas às mais eficientes de determinado grupo, (3) o diagnóstico de inputs utilizados de maneira improdutiva, e ainda (4) o reconhecimento das DMUs com melhores práticas que, sendo mais parecidas com dadas DMUs menos eficientes do grupo, possam ser consideradas benchmarks.

Em termos matemáticos, a DEA calcula a eficiência por meio da razão entre uma soma ponderada de saídas (outputs) e uma soma ponderada de entradas (inputs). O peso para cada fator de ponderação (insumos e produtos) é obtido por meio da resolução de um problema de programação fracionária, em que cada unidade analisada maximiza sua eficiência (Mello et al., 2003).

Os pesos para variáveis de entrada e saída do modelo geral da DEA podem ser obtidos a partir da solução do modelo proposto por Charnes et al. (1978), dado pelas equações a seguir:

$$
\max E_{j}=\sum_{r=1}^{s} u_{r} \cdot y_{r 0} / \sum_{i=1}^{m} v_{i} \cdot x_{i 0}
$$

a saber:

$$
\begin{gathered}
\left(\sum_{r=1}^{s} u_{r} y_{r j} / \sum_{i=1}^{m} v_{i} x_{i j}\right) \leq 1, j=1,2, \ldots, n \\
u_{r} \geq 0, \quad r=1,2, \ldots, s \\
v_{i} \geq 0, \quad i=1,2, \ldots, m
\end{gathered}
$$

sendo a $\mathrm{DMU}_{0}$ a $\mathrm{DMU}$ sob avaliação ou análise; $\mathrm{w}_{0}$ a eficiência relativa da $\mathrm{DMU}_{0}$; $\mathrm{Y}_{\mathrm{r} o}$ e $\mathrm{x}_{\mathrm{io}}$ os dados de saídas e entradas para a $\mathrm{DMU}_{0} ; j$ o índice da $\mathrm{DMU}, j=1 \ldots, n$; r o índice da saída, com $r=1, \ldots$, s; $i$ o índice da entrada, $i=1, \ldots, m ; y_{r j}$ o valor da r-ésima saída para a j-ésima DMU; $x_{i j} O$ valor da $i$-ésima entrada para a $j$-ésima DMU; $U_{r}$ o peso associado à r-ésima saída; e $v_{i}$ o peso associado à $i$-ésima entrada. Observe-se que: se $E_{j}=1$, a $D M U_{0}$ é eficiente quando comparada às demais unidades consideradas no modelo e se $0 \leq E_{j}<1$, a $D M U_{0}$ é ineficiente.

Segundo Silva et al. (2012), as DMUs que forem consideradas eficientes terão coeficiente 1 ou 100\%, chamados de fronteira Pareto-Eficiente. A única restrição da técnica é que a DMU esteja dentro ou na fronteira de eficiência.

Mello et al. (2005) salientam que a eficiência estimada pela DEA é uma quantidade ligada ao quociente entre uma soma ponderada dos produtos (outputs) e uma soma ponderada dos recursos (inputs). Para que os pesos não sejam arbitrários (eliminando, assim, a subjetividade da análise), a técnica 
permite que cada empresa analisada escolha os pesos mais apropriados, ou seja, aqueles que maximizem essa razão. Entretanto, isso não pode ser feito de forma totalmente livre, já que o resultado tem que ser uma eficiência, isto é, um número, entre 0 (zero) e 1 (um). A programação matemática utilizada pela técnica é apresentada na seguinte equação:

$$
\text { Maximizar } \frac{u Y_{0}}{v X_{0}} \text { sujeito a } \frac{u Y_{k}}{v X_{k}} \leq 1 \text {, para todo } \mathrm{K}
$$

onde $u$ são os pesos atribuídos aos outputs da empresa $O, Y$ são os outputs da empresa $O, v$ são os pesos atribuídos aos inputs da empresa $O, X$ são os inputs das empresas $O$, e $K$ representa o número de empresas. Assim, os pesos que uma empresa $O$ escolhe, quando aplicados a ela mesma e às outras (no total de $k$ empresas), não podem dar um quociente superior à unidade. Essa restrição é aplicada tantas vezes quanto for o número de empresas, ou seja, é uma restrição para cada empresa analisada.

Charnes et al. (1978) ampliaram os seus estudos utilizando múltiplos inputs e outputs, criando o denominado modelo CCR (homenagem aos autores), o qual considera retornos constantes à escala na fronteira e, por isso, é também conhecido como Constant Returns to Scale (CRS). Esse modelo permite uma avaliação objetiva da eficiência global e identifica as fontes e estimativas de montantes das ineficiências identificadas (Casa Nova, 2002).

\begin{abstract}
A característica essencial do modelo CCR é a redução de múltiplos produtos e múltiplos insumos (para cada DMU) para um único produto 'virtual' e um único insumo 'virtual'. Para uma DMU, a razão entre esse produto virtual e o insumo virtual fornece uma medida de eficiência que é função dos multiplicadores. Essa proporção, que será maximizada, forma a função-objetivo para a DMU "O" sendo avaliada. (Charnes et al., 1994, p. 40).
\end{abstract}

Coelli et al. (2005) expressam esse modelo por:

MIN $\theta, \lambda \theta$

$$
\begin{gathered}
\text { Sujeito } a:-y_{i}+Y \lambda \geq 0 \\
\theta x_{i}-X \lambda \geq 0 \\
\lambda \geq 0
\end{gathered}
$$

em que $\theta$ q é o escore de eficiência de uma dada DMU; y é o produto da DMU e $x$ é o insumo. $X$ é a matriz de insumos $(n \times k)$ e $Y$ é a matriz de produtos $(n \times m) ; \lambda$ é o vetor de constantes que multiplica a matriz de insumos e produtos.

Em 1984, Banker et al. (1984), buscando eliminar a necessidade de rendimentos constantes de escala, criaram uma nova modelagem para o DEA, o modelo BCC, também conhecido como Variable Returns to Scale (VRS), em que se consideram retornos variáveis aqueles que podem assumir rendimentos crescentes e decrescentes de escala. Para Casa Nova (2002), esse modelo estabelece distinção entre ineficiências técnicas e de escala, estimando a eficiência técnica pura, a uma dada escala de operações, e identificando se 
estão presentes ganhos de escala crescente, decrescente ou constante para futura exploração.

Para Gomes \& Baptista (2004), uma DMU opera com retornos constantes à escala quando o escore de eficiência de escala for igual a um. Entretanto, se a medida de eficiência de escala for menor que a unidade, poderá ocorrer a presença de rendimentos crescentes ou decrescentes de escala. Nesse caso, devem-se comparar os escores de eficiência técnica no modelo com retornos não crescentes e no modelo com retornos variáveis, de modo que, se tais valores forem diferentes, a DMU terá retornos crescentes à escala, e, se forem idênticos, terá retornos decrescentes à escala.

Segundo Coelli et al. (2005), o modelo BCC pode ser representado por:

MIN $\theta, \lambda \theta$

$$
\begin{gathered}
\text { Sujeito } a:-y_{i}+Y \lambda \square 0 \\
\theta x_{i}-X \lambda \square 0 \\
N_{1} \lambda \square 0
\end{gathered}
$$

em que $N_{1}$ é um vetor $(N \times 1)$ de algarismos unitários.

Marinho \& Cardoso (2007) dão um exemplo hipotético de construção de fronteiras de eficiência utilizando dois modelos de DEA, como apresentado na Figura 3. Os autores indicam que o modelo CCR admite uma fronteira de eficiência com retornos constantes de escala, ou seja, uma reta passando pela origem dos eixos cartesianos; e o modelo BCC, admite retornos variáveis de escala.

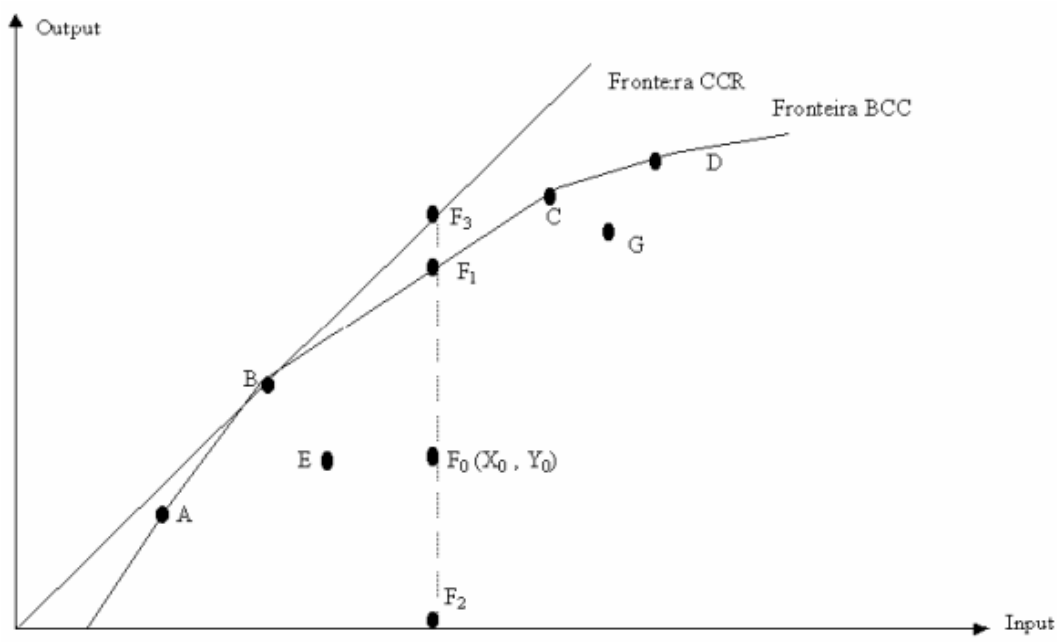

Figura 1 - Fronteiras de Eficiência - Modelos CCR e BCC Fonte: Marinho \& Cardoso (2007, p. 17).

Conforme a Figura 1, Marinho \& Cardoso (2007) mencionam que as supostas unidades A, B, C, D e Fl, localizadas sobre a fronteira do modelo BCC, são eficientes nesse modelo. A unidade F3 é eficiente no modelo CCR, mas não faria parte da amostra analisada no modelo BCC, pois nenhuma unidade pode 
estar localizada acima da fronteira de eficiência de nenhum modelo. As unidades E, FO, F2 e G não são eficientes em nenhum dos dois modelos, pois estão localizadas abaixo das fronteiras. Por exemplo, de acordo com o modelo CCR, a unidade F0 poderia expandir a sua produção (output) até o nível de produção da suposta unidade F3, sem aumentar o uso de recursos (inputs) fixado no mesmo nível da unidade F2.

Tanto o modelo CCR quanto o BCC podem ser analisados pela ótica da orientação para insumos ou pela orientação para o produto. Haynes \& Dinc (2005) mencionam que a técnica DEA pode ser orientada para input e output. $O$ modelo orientado para input busca maximizar a redução proporcional nas variáveis de input, enquanto mantém o nível de output constante. Já o modelo orientado para output, maximiza o aumento proporcional das variáveis de output mantendo o mesmo nível de inputs.

Segundo Gomes \& Baptista (2004), a escolha da orientação não exerce grande influência na magnitude do valor de eficiência técnica, e o critério de escolha dependerá da finalidade do estudo, ou seja, se o objetivo é regularizar o consumo de insumos ou possibilitar o aumento da produção.

Diante desse contexto, a implementação da técnica DEA estabelece três fases principais (Golany \& Roll, 1989): 1) definição e seleção das DMUs a serem analisadas; 2) seleção das variáveis (inputs e outputs) relevantes e apropriadas para estabelecer a eficiência das DMUs selecionadas e 3) aplicação dos modelos DEA.

Diante desse contexto, esta pesquisa, ao utilizar a metodologia DEA, traz uma contribuição pois diferencia-se dos demais estudos relacionados ao buscar analisar a eficiência relativa sob o ponto de vista da missão das UFs, voltada para o tripé: atividades de ensino, de pesquisa e de extensão.

\section{PROCEDIMENTOS METODOLÓGICOS}

\subsection{Tipologia}

A fim de atender aos objetivos metodológicos, trata-se de uma pesquisa descritiva, de natureza quantitativa. Utiliza-se o método quantitativo devido ao fato de utilizar a metodologia DEA e as técnicas estatísticas descritivas, para avaliar como estão nível de eficiência relativa das Universidades Federais em atividades de ensino, pesquisa e extensão. As características descritivas foram aplicadas no intuito de conhecer e interpretar a realidade das UFs, identificando suas características específicas e indicadores, de forma que possam ser classificados e interpretados os fenômenos nelas ocorridos.

Quanto ao método utilizado, a pesquisa se enquadra como Não Experimental/Positivista, uma vez que o fenômeno pesquisado é considerado em seu estado natural (Bertassi, 2016).

Já em relação às técnicas de coleta de dados, foi realizada uma pesquisa documental e Ex-Post-Facto, a fim de extrair dados e indicadores relacionados às UFs estudadas. Quanto à pesquisa documental, Marconi \& Lakatos (2007) afirmam que sua principal característica é que a fonte de coleta de dados está restrita a documentos escritos ou não, além de serem feitas na ocasião de acontecimento do fato ou posteriormente. 
O tipo de amostragem utilizada nesta pesquisa foi a não probabilística intencional, uma vez que foram utilizadas como amostras, as UFs que se enquadram nos critérios estabelecidos da pesquisa. A característica principal das técnicas de amostragem não probabilística é a de que, não fazendo uso de formas aleatórias e seleção (Marconi \& Lakatos, 2007).

E por fim, quanto às técnicas de análise de dados, foi utilizada Análise por Envoltória de dados (DEA) possibilitando, por meios estatísticos, inferir a eficiência relativa das UFs nas atividades de ensino, pesquisa e extensão, bem como sua evolução, além de verificar o peso das variáveis selecionadas.

\subsection{Procedimentos, Técnicas de Coleta de Dados e Período de Análise}

Para a obtenção dos dados necessários a análise, os mesmos foram extraídos dos Relatórios de Gestão das Universidades Federais em seus sítios e via solicitação a Ouvidoria Federal, por meio do Sistema Eletrônico do Serviço de Informações ao Cidadão (e-SIC), com base na Lei n 12.527/201 1, Lei de Acesso à Informação (Brasil, 2011).

Os resultados das IFES são apresentados no seu Relatório de Gestão elaborados pelas mesmas, permitindo que o TCU acompanhe como os gastos públicos estão sendo aplicados, possibilitando assim, que sejam realizadas avaliações de desempenho. O Relatório de Gestão acaba por ser um dos artefatos para a prestação de contas, pois possuem informações financeiras, patrimoniais, indicadores de desempenho, dentre outras, que evidenciam o montante de recursos recebidos, como e onde foram aplicados e os resultados quantitativos e qualitativos gerados. Entretanto, não basta conhecer os resultados e seus indicadores, é necessário analisá-los no sentido de verificar se a aplicação dos recursos está sendo eficiente, bem como comparar estes resultados com outras instituições.

O período de análise refere-se aos anos de 2013 a 2017, o que o caracteriza como um estudo longitudinal. O período de análise se baseia no período pósReuni, o qual as universidades pararam de receber recursos públicos advindos do programa, que finalizou em 2012. De posse dos dados foram feitos levantamentos sobre a eficiência relativa de UFs no que diz respeito as atividades de ensino, pesquisa e extensão, utilizando a metodologia da DEA.

\subsection{Objeto de Estudo e Amostragem}

Golany \& Roll (1989) ressaltam a importância e o cuidado em determinar o tamanho da amostra antes da definição das variáveis. Uma grande quantidade de DMU's pode diminuir a homogeneidade dentro do conjunto analisado, aumentando a possibilidade de os resultados serem afetados por fatores que foram desconsiderados pelo modelo. Por outro lado, se o tamanho da amostra for menor que a quantidade de inputs e outputs, a análise pode resultar em todas as DMU's serem eficientes. Alguns autores recomendam que o número de unidades tomadoras de decisão (DMU's) deve ser no mínimo duas vezes o número de inputs e outputs considerados. Embora não haja uma regra geral, Banker et al. (1984) sugerem que o número de DMUs deve ser pelo menos três 
vezes o número de variáveis, enquanto Cook et al. (2014) propõem que seja pelo menos duas vezes o número de variáveis.

Para isso, neste estudo, a população é composta de Universidades Federais do Brasil, como unidades de análise da pesquisa, perfazendo um total de 34 UFs estudadas, conforme Figura 2.

\begin{tabular}{|r|l|l|r|}
\hline & \multicolumn{1}{|c|}{ NOME } & \multicolumn{1}{|c|}{ SIGLA } & CRIAÇÃO \\
\hline 1 & Universidade Federal da Bahia & UFBA & 1946 \\
\hline 2 & Universidade Federal de Alfenas & UNIFAL & 2005 \\
\hline 3 & Universidade Federal de Ciências da Saúde de Porto & UFCSPA & 2008 \\
& Alegre & UFG & 1960 \\
\hline 4 & Universidade Federal de Goiás & UNIFEI & 2002 \\
\hline 5 & Universidade Federal de Itajubá & UFJF & 1960 \\
\hline 6 & Universidade Federal de Juiz de Fora & UFLA & 1994 \\
\hline 7 & Universidade Federal de Lavras & UFMT & 1970 \\
\hline 8 & Universidade Federal de Mato Grosso & UFMS & 1979 \\
\hline 9 & Universidade Federal de Mato Grosso do SUl & UFMG & 1927 \\
\hline 10 & Universidade Federal de Minas Gerais & UFPE & 1967 \\
\hline 11 & Universidade Federal de Pernambuco & UNIR & 1982 \\
\hline 12 & Universidade Federal de Rondônia & UFRR & 1987 \\
\hline 13 & Universidade Federal de Roraima & UFSC & 1960 \\
\hline 14 & Universidade Federal de Santa Catarina & UFSM & 1960 \\
\hline 15 & Universidade Federal de Santa Maria & UFSJ & 2002 \\
\hline 16 & Universidade Federal de São João del-Rei & UFU & 1978 \\
\hline 17 & Universidade Federal de Uberlândia & UFV & 1969 \\
\hline 18 & Universidade Federal de Viçosa & UFABC & 2005 \\
\hline 19 & Universidade Federal do ABC & UFAC & 1974 \\
\hline 20 & Universidade Federal do Acre & UFAM & 1962 \\
\hline 21 & Universidade Federal do Amazonas & UFES & 1961 \\
\hline 22 & Universidade Federal do Espírito Santo & UNIRIO & 1979 \\
\hline 23 & Universidade Federal do Estado do Rio de Janeiro & UFOPA & 2009 \\
\hline 24 & Universidade Federal do Oeste do Pará & UNIPAMPA & 2008 \\
\hline 25 & Universidade Federal do Pampa & UFPR & 1950 \\
\hline 26 & Universidade Federal do Paraná & UFRB & 2005 \\
\hline 27 & Universidade Federal do Recôncavo da Bahia & UFRJ & 1965 \\
\hline 28 & Universidade Federal do Rio de Janeiro & FURG & 1969 \\
\hline 29 & Universidade Federal do Rio Grande & UFRGS & 1968 \\
\hline 30 & Universidade Federal do Rio Grande do Sul & UNIVASF & 2002 \\
\hline 31 & Universidade Federal do Vale do São Francisco & UFVJM & 2005 \\
\hline 32 & Universidade Federal dos Vales do Jequitinhonha e & UFRA & 2002 \\
\hline 33 & Universidade Federal Rural da Amazônia & UFRRJ & 1968 \\
\hline 34 & Universidade Federal Rural do Rio de Janeiro & \\
\hline
\end{tabular}

Figura 2 - Universidades federais estudadas

Fonte: Elaboração própria com base nas Instituições do MEC (BRASIL, 2017).

Vale ressaltar que do universo de 63 UFs brasileira até 2017, excluiu-se 39 UFs as quais tinham dados faltantes ou então que não disponibilizaram os dados, sendo que 11 UFs não possuíam os dados sobre ensino (ou por não disponibilizarem os dados primários ou por serem universidades novas), impossibilitando os cálculos dos indicadores do TCU. Entretanto, para o estudo sobre as atividades de pesquisa, 7 universidades não dispunham de todos os 
dados, todas elas por serem novas. Já para as atividades de extensão 27 não disponibilizaram os dados, percebendo-se aí um delimitador da amostra.

\subsection{Método}

A fim de atender ao objetivo do trabalho, foi utilizada a Análise por Envoltória de Dados (Data Envelopment Analysis - DEA). Conforme abordado no referencial teórico, a DEA é uma técnica baseado em programação linear para calcular a eficiência relativa das unidades e foi introduzido por Charnes et al. (1978), fundamentados nos estudos de Koopmans (1951), Debreu (1951) e Farrell (1957).

Para a realização da pesquisa, foi utilizado o modelo de análise de eficiência BCC, uma vez que este determina a fronteira de eficiência levando em consideração retornos variáveis de escala, na qual considera que um acréscimo no input poderá promover um acréscimo no output, não necessariamente proporcional, ou até mesmo um decréscimo.

Além disso, foi utilizado o modelo de análise de eficiência BCC orientado para o produto, uma vez que a busca da eficiência por meio da maximização da produção apresenta-se mais condizente à natureza das atividades de ensino, pesquisa e extensão das UFs, ou seja, maximizar o movimento em direção à fronteira por meio do acréscimo proporcional de outputs, mantendo constantes os inputs. Assim, foi constituído um conjunto de referência (benchmarks) para as unidades ineficientes, fornecendo escores de (in)eficiência separados para as atividades (ensino, pesquisa e/ou extensão) das referidas UFs.

Com os dados do período de 2013 a 2017, referentes a 34 UFs, os cálculos da DEA foram efetuados com o uso do software livre EMS - versão 1.3, o que permitiu avaliar o nível de eficiência relativa de Universidades Federais brasileiras em relação as atividades de ensino, pesquisa e extensão.

\subsection{Seleção das Variáveis}

A fim de analisar separadamente a eficiência relativa em cada atividade do tripé ensino, pesquisa e extensão, as variáveis foram direcionadas às atividades as quais se identificam. Para calcular a eficiência relativa referente às atividades de ensino de graduação foram consideradas as seguintes variáveis, conforme Figura 3.

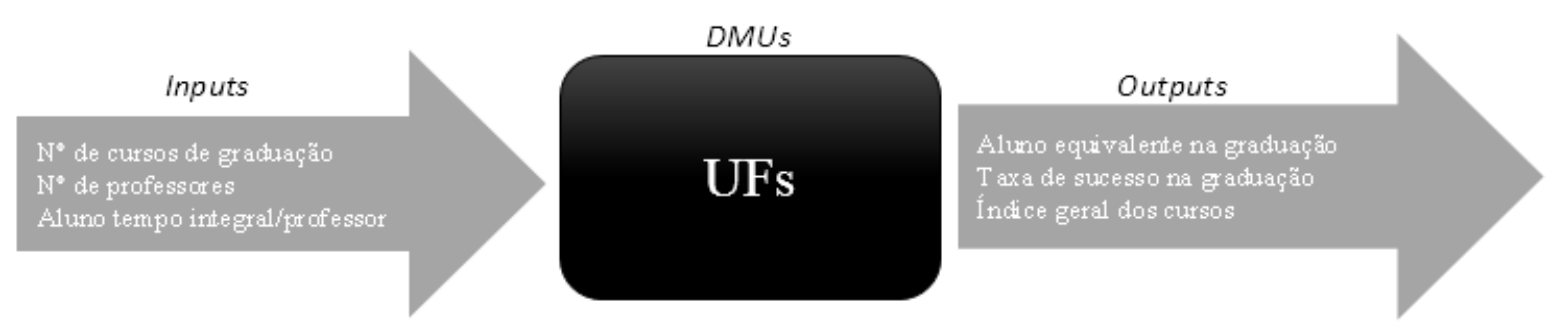

Figura 3 - Variáveis de Ensino Fonte: Elaboração própria (2019). 
A relação do número de cursos de bacharelado está direcionada à formação e preparação dos alunos para o exercício de diferentes profissões, sendo assim, é por meio destes que os alunos poderão atuar no mercado de trabalho. A expansão educacional aumenta a produtividade do trabalho, contribuem para o crescimento econômico, aumenta os salários, promove uma maior igualdade social e contribui para diminuição da pobreza (Barros et al., 2002).

Entretanto, a formação do aluno na graduação também depende, além da oferta de cursos, da atuação do professor. Neves \& Malta (2014) mencionam a importância dos docentes no desenvolvimento de atividades de ensino, pesquisa e extensão, visto que estes contribuem no processo de aprendizagem, tornando-se mediadores e articuladores nos conhecimentos dos estudantes em busca de uma estruturação social. Portanto, a atuação docente na educação superior não é restrita à sala de aula, nem tampouco à pesquisa ou ao administrativo, o docente precisa desenvolver essas atividades de forma concomitante e complementar. Assim, entende-se que quanto maior o número de professores relativamente ao de alunos, melhor será a atenção e apoio a estes, favorecendo uma produtividade maior de recursos docentes, bem como no desenvolvimento de suas atividades.

Considerando que a taxa de sucesso na graduação é tida em relação ao número de alunos que concluem o curso no tempo de duração prevista, esta acaba por refletir na qualidade e nos investimentos por parte da instituição. Assim, entende-se que não basta formar a maior quantidade de alunos (resultado da taxa de sucesso), mas é necessário que a instituição de ensino seja qualitativamente bem avaliada em suas ações. Dessa forma, inclui-se como output o IGC, que mede a qualidade da instituição de ensino superior, calculando a média ponderada de todas as notas dos cursos de graduação (input).

Em relação às atividades de pesquisa, para calcular a eficiência relativa foram consideradas as seguintes variáveis, conforme Figura 4.

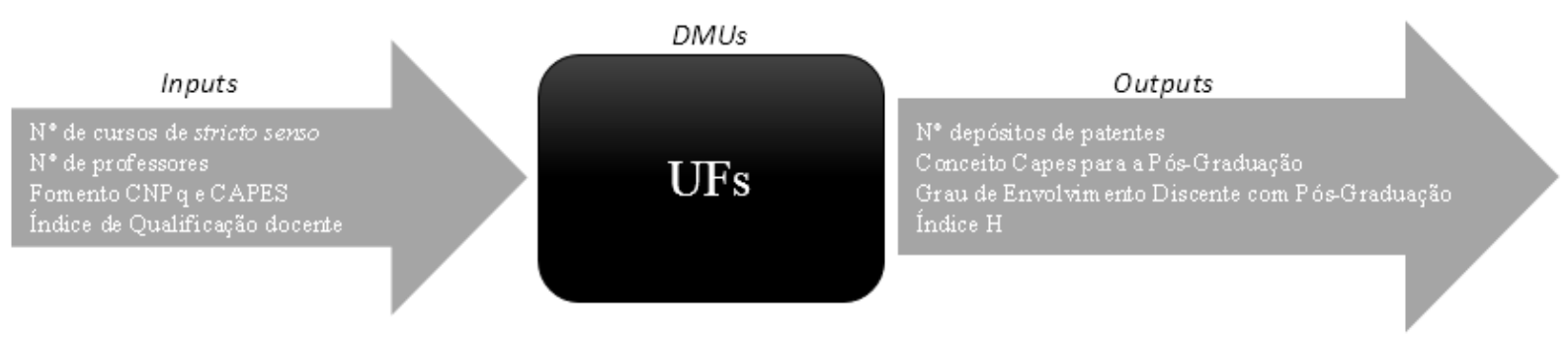

Figura 4 - Variáveis de Pesquisa Fonte: Elaboração própria (2019).

Considerando que os professores é a principal ponte para que a UF realize sua missão, novamente o número de docentes foi considerado como input, visto que eles também realizam atividades de pesquisas. Além disso, Menezes \& Santos (2001) mencionam que o IQCD está relacionado à qualidade do ensino de graduação e de pós-graduação e com o volume de pesquisas desenvolvidas.

Apesar da graduação realizar pesquisas e alunos participarem de iniciação científica, a grande parte das pesquisas que possuem impacto advém dos cursos Revista Contabilidade Vista \& Revista, ISSN 0103-734X, Universidade Federal de Minas Gerais, 73 Belo Horizonte, v. 32, n. 2, p. 59-96, maio/ago. 2021. 
de pós-graduação. Severino (2006, p. 51-52) menciona que "a pós-graduação é um dos melhores segmentos do sistema educacional brasileiro sob o critério do nível de qualidade alcançado e vem contribuindo significativamente para a construção de um retrato mais fiel da realidade nacional, graças à sistematização e à institucionalização da prática científica de investigação, ao mesmo tempo em que forma novas gerações de pesquisadores". Assim, o número de cursos de pós-graduação foi utilizado com input.

Consoante a isso, um número maior de cursos de pós-graduação permite um número elevado de discentes de graduação envolvidos com um nível de formação mais elevado, tendo um efeito positivo na formação destes, uma vez que tal envolvimento ocasiona mais contato com atividades de pesquisa nas quais o aluno tem a oportunidade de solidificar conhecimentos adquiridos em sala de aula e envolver-se com estudos mais avançados.

A CAPES e o CNPq são as principais fontes de fomento governamental destinados à pesquisa, considerou-se esta variável como input, visto que quanto mais incentivos financeiros os pesquisadores tiverem, maiores as oportunidades de desenvolvimentos de pesquisas.

Com o passar dos anos e da crescente responsabilidade dos cientistas pela solução de problemas sociais e econômicos, a produção de inovações comerciáveis, como resultados de pesquisa acadêmica se tornou um fato relevante. Assim, por meio das pesquisas desenvolvidas, Chaves (2009) menciona que as UFs tem sido grandes geradoras de inovação tecnológica. Entretanto, foi considerado o número de pedidos de patente registrado no INPI, isso se deve ao fato de que o processo de registro é longo, difícil e pode ser custoso. Além disso, o fato da patente ser concedida não significa que ela venha a ser licenciada para algum interessado ou venha a ser explorada de alguma maneira. Mueller \& Perucchi (2014) menciona que o prazo médio entre solicitação e resposta, que pode ser favorável ou não à concessão da carta-patente, é de 10 anos, e que o valor da patente é depende do potencial de comercialização ou exploração econômica que a patente apresenta.

O conceito CAPES aplicado às UFs avaliam o desempenho dos programas de pós-graduação por meio de cinco quesitos, com diferentes pesos diferentes na composição da nota final: a) proposta do programa; b) corpo docente; c) corpo discente, teses e dissertações; d) produção intelectual, e; e) inserção social. Dessa forma, os resultados subsidiam o estabelecimento de políticas para a área de pós-graduação stricto sensu, bem como para a aplicação das ações de fomento, como bolsas de estudo, auxílios, apoios, entre outros.

Em relação à difusão das pesquisas, considerou-se como output o Índice H, pois é considerado um indicador de qualidade em produção científica a qual serve para avaliar a relevância do trabalho de pesquisadores, uma vez que quantifica a produtividade e o impacto de pesquisas individuais ou em grupos baseando-se nos artigos (papers) mais citados. Costas \& Bordons (2007, p.194) afirmam que o h-index é considerado um bom indicador bibliométrico, preferível a usar apenas o $n^{\circ}$ total de trabalhos produzidos, o $n^{\circ}$ total de citações, o $n^{\circ}$ citações por artigo ou o $\mathrm{n}^{\circ}$ de artigos mais citados.

E por fim, para calcular a eficiência relativa referente as atividades de extensão foram consideradas as seguintes variáveis, conforme Figura 5. 


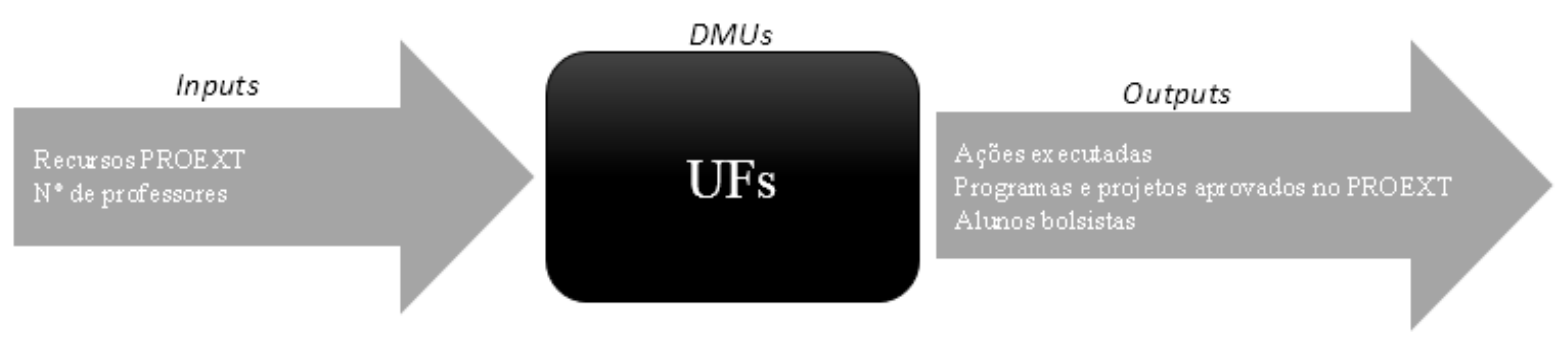

Figura 5 - Variáveis de Extensão

Fonte: Elaboração própria (2019).

Novamente os números de professores das UFs foi considerado como input, destacando a importância da atuação destes na integração da instituição com a sociedade.

O governo instituiu em 2008, o Programa de Extensão Universitária (PROEXT) com o objetivo de ampliar a interação das universidades com a sociedade e a formalização da destinação de recursos aos projetos de base extensionista, considerou-se os recursos repassados às UFs como input, visto que esses possibilitaram a execução de programas e projetos em benefício da sociedade.

A quantidade de programas e projetos submetidos e aprovados (output) demonstra como um dos pilares da universidade vem ganhando significância, além de que seus docentes estão se mostrando cada vez mais dispostos a elaborar, submeter e desenvolver projetos extensionistas.

Vale ressaltar que nem sempre esses programas e projetos são contemplados com recursos via editais PROEXT. Entretanto, as UFs executam ações mediante recursos próprios ou até mesmo com parcerias privadas, por isso o número de ações desenvolvidas foi considerado input.

Já em relação aos alunos bolsistas da extensão, estes foram considerados como output, uma vez que, a ajuda financeira estimula a interação dos estudantes da universidade com outros setores da sociedade, por meio de atividades que contribuam para a sua formação acadêmica, profissional e para o exercício da cidadania.

\section{ANÁLISE E DISCUSSÃO DOS RESULTADOS}

A fim de atingir o objetivo proposto, buscou-se avaliar o nível de eficiência relativa de UFs brasileiras utilizando a DEA nas atividades de ensino, pesquisa e extensão. Para isso, primeiramente realiza-se a estatística descritiva dos dados, para posteriormente apresentar a análise da eficiência relativa das UFs nas atividades.

\subsection{Estatística Descritiva das Variáveis}

A primeira análise foi a verificação por meio da matriz de correlação entre as variáveis de inputs e outputs selecionadas para o estudo, visto que é prérequisito que as variáveis selecionadas tenham correlação positiva (Chen et al., 2012). 
Para as atividades de ensino, pode-se observar, na Tabela 1, que as variáveis selecionadas atendem aos pressupostos, pois todas elas são correlacionadas positivamente, sendo que as variáveis Professor e Aluno Equivalente na Graduação foram as que apresentaram maior grau de correlação.

\section{Tabela 1}

Matriz de Correlação de Ensino

\begin{tabular}{|c|c|c|c|c|c|c|}
\hline \multirow{7}{*}{$\begin{array}{l}\text { CURSOS } \\
1,0000\end{array}$} & PROF & $A / P$ & AGE & TSG & IGC & ENSINO \\
\hline & 0,8686 & 0,3574 & 0,8485 & 0,3393 & 0,2496 & CURSOS \\
\hline & 1,0000 & 0,4703 & 0,9600 & 0,4472 & 0,4995 & PROF \\
\hline & & 1,0000 & 0,5811 & 0,4523 & 0,4795 & AP \\
\hline & & & 1,0000 & 0,5218 & 0,5184 & AGE \\
\hline & & & & 1,0000 & 0,5090 & TSG \\
\hline & & & & & 1,0000 & IGC \\
\hline
\end{tabular}

Fonte: Elaboração própria (2019).

Já em relação à Tabela 2, na qual se apresentam as estatísticas descritivas dessa atividade, nota-se que a média em relação ao número de cursos é de 80,24, visto que o desvio padrão é de 43,59, indicando uma amostra não tão uniforme, uma vez que as UFs possuem tamanho e tempo de fundação distintos. Sendo assim, o número de cursos máximo é de 180 da UFRJ e o mínimo é de 11 da UFCSPA.

Devido à mesma situação de grandeza e tempo, a variável número de professores em exercício apresenta dispersão proporcional, apontando uma média de 1426,46, com desvio padrão de 983,71. O máximo de professores em uma instituição é de 4.12 da UFRJ e o mínimo foi de 254 da UFOPA.

Em relação à variável A/P, tem-se uma média de 12,06 de alunos por professor, com um desvio padrão de apenas 2,57, mostrando uma situação mais próxima à uniformidade por ser uma variável relacional. A máxima dessa variável foi de 18,6 da UFAC e a mínima de 3,82 da UNIPAMPA.

Para a variável aluno equivalente na graduação, tem-se 19517,62 de média e 12410,46 de desvio padrão, verificando-se a discrepância entre os tamanhos e tempo de vida das UFs, pois o número máximo de alunos foi de 54.449 da UFRJ e o mínimo de 1.843,73 da UFOPA.

A variável taxa de sucesso na graduação teve uma média de 47,04, com desvio padrão de 13,01. Considerando a variável que apresenta o desempenho das UFs por meio da relação de alunos diplomados com o número de alunos ingressantes, tem-se um número máximo de 90 da UFRB e mínimo de 3,98 da UFOPA.

E, por fim, o índice geral de cursos, que apresentou uma média 3,45 com desvio padrão de 0,5, mostra mais uniformidade na qualidade dos cursos das UFs. A máxima dessa variável foi de 4,35 da UFRGS e a mínima de 1,93 da UFOPA.

Diante disso, observa-se que as variáveis apresentam uma maior dispersão oriunda do tamanho e tempo de fundação da UFs, e, ao analisar as variáveis de relação, nota-se que o desvio padrão reduz bastante, indicando que, apesar dessa distinção de tamanho, elas apresentam desempenho equivalente. 
Tabela 2

Estatística Descritiva das Variáveis de Ensino

\begin{tabular}{lrrrrrr}
\hline Estatística & CURSOS & PROF & A/P & AGE & TSG & IGC \\
Média & 80,24 & 1429,46 & 12,06 & 19517,62 & 47,04 & 3,45 \\
Desvio Padrão & 43,59 & 83,71 & 2,57 & 12410,46 & 13,01 & 0,50 \\
Máxima & 180,00 & 126,00 & 18,60 & 54449,00 & 90,00 & 4,35 \\
Mínima & 11,00 & 254,00 & 3,82 & 1843,73 & 3,98 & 1,93 \\
\hline
\end{tabular}

Fonte: Elaboração própria (2019).

Para as atividades de pesquisa, a Tabela 3 apresenta a correlação das variáveis selecionadas. Observa-se que essas atendem aos pressupostos, visto que todas são correlacionadas positivamente. A correlação das variáveis número de cursos stricto senso com Professor foi a que apresentou maior grau de correlação, seguida da correlação entre cursos strictu senso e fomento advindos da CAPES e do CNPq.

\section{Tabela 3}

Matriz de Correlação de Pesquisa

\begin{tabular}{lllllllll}
\hline CSS & PROF & FOMCC & IQCD & DP & CCPG & GEPG & HINDEX & PESQUISA \\
1,0000 & 0,9577 & 0,8329 & 0,3215 & 0,6986 & 0,6846 & 0,8043 & 0,7215 & CSS \\
& 1,0000 & 0,7832 & 0,1944 & 0,6747 & 0,5811 & 0,6956 & 0,6769 & PROF \\
& & 1,0000 & 0,3056 & 0,6088 & 0,6979 & 0,7547 & 0,7946 & FOMCC \\
& & & 1,0000 & 0,3534 & 0,5167 & 0,5204 & 0,3697 & IQCD \\
& & & & 1,0000 & 0,5443 & 0,6206 & 0,5333 & DP \\
& & & & & 1,0000 & 0,7826 & 0,6296 & CCPG \\
& & & & & & 1,0000 & 0,6989 & GEPG \\
\hline
\end{tabular}

Fonte: Elaboração própria (2019).

A Tabela 4 apresenta as estatísticas descritivas da atividade de pesquisa. Nota-se que, em relação ao número de cursos stricto senso, a média é de 35,52 e o desvio padrão é de 27,76, indicando que há uma dispersão considerável entre as UFs. Sendo assim, o número de cursos máximo é de 120 da UFRJ enquanto o mínimo é de 4 da UFCSPA.

A variável número de professores tem a mesma estatística para todas as atividades.

Em relação à variável fomento da CAPES e do CNPq, tem-se uma média de $R \$ 22.819 .693,51$ recebidos, com um desvio padrão de $R \$ 33.097 .204,82$. $O$ valor máximo recebido foi de $R \$ 179.992 .154,66$ da UFRJ e o mínimo de $R \$$ $620.416,61$ da UFOPA.

Para a variável índice de qualificação docente, tem-se 4,29 de média e 0,39 de desvio padrão, mostrando uma maior uniformidade entre a qualificação dos professores das UFs, com o indicador máximo de 4,29 da FURG e da UFMS e mínimo de 3,18 da UFAC.

Já para a variável depósito de patentes, a média foi de 10,59 com desvio padrão de 14,14, apontando uma discrepância entre a inovação dependendo 
da UF, pois o número máximo de pedidos foi 70 da UFMG, enquanto o mínimo foi zero de várias UFs.

Em relação ao conceito CAPES de pós-graduação, tem-se uma média de 3,90 com desvio padrão de 0,68 , apontando mais uniformidade na qualidade dos cursos das UFs. A máxima dessa variável foi de 6,43 da UNIRIO e a mínima 2,89 da UFRR.

A variável grau de envolvimento de alunos na pós-graduação tem uma média de 0,12 com desvio padrão de 0,07, demonstrando que as UFs que tiveram maior envolvimento foram de $30 \%$ da UFRGS e o menor $2 \%$ da UNIPAMPA e UFAC.

Por fim, tem-se o índice $\mathrm{H}$, com média de 15,9 e desvio padrão de 9,42. O indicador apresenta uma maior variação entre a relação de publicações e citações dos envolvidos na UF, visto que o maior índice é de 45 da UFRJ e o menor é de 3 da UFRR.

Diante disso, observa-se que, apesar da qualificação dos professores e dos conceitos dos cursos serem mais uniformes, os recursos recebidos, bem como o número de cursos e o índice $\mathrm{H}$ apresentam as maiores dispersões.

\section{Tabela 4}

Estatística Descritiva das Variáveis de Pesquisa

\begin{tabular}{lllllllll}
\hline Estatística & CSS & PROF & FOMCC & IQCD & DP & CCPG & GEPG & HINDEX \\
Média & 35,52 & 1429,46 & 22819693,51 & 4,29 & 10,59 & 3,90 & 0,12 & 15,90 \\
Desvio Padrão & 27,76 & 983,71 & 33097204,82 & 0,39 & 14,14 & 0,68 & 0,07 & 9,42 \\
Máxima & 120,00 & 4126,00 & 179992154,66 & 5,24 & 70,00 & 6,43 & 0,30 & 45,00 \\
Mínima & 4,00 & 254,00 & 620416,61 & 3,18 & 0,00 & 2,89 & 0,02 & 3,00 \\
\hline
\end{tabular}

Fonte: Elaboração própria (2019).

Para as atividades de extensão, a Tabela 5 apresenta a correlação das variáveis selecionadas, sendo possível observar que elas atendem aos pressupostos, uma vez que todas são correlacionadas positivamente. A correlação das variáveis recursos advindos do PROEXT/MEC com os Programas e Projetos aprovados pelo PROEXT foi a que apresentou maior grau de correlação.

Tabela 5

Matriz de Correlação de Extensão

\begin{tabular}{llllll}
\hline PROF & RPRO & AEXE & AB & PPPROEXT & EXIENSÃO \\
1,0000 & 0,4079 & 0,3433 & 0,6327 & 0,4421 & PROF \\
& 1,0000 & 0,1135 & 0,2844 & 0,8794 & RPRO \\
& & 1,0000 & 0,1908 & 0,1279 & AEXE \\
& & & 1,0000 & 0,3587 & AB \\
& & & & 1,0000 & PPPROEXT \\
\hline
\end{tabular}

Fonte: Elaboração própria (2019).

A Tabela 6 apresenta as estatísticas descritivas da atividade de pesquisa, lembrando que a variável número de professores tem a mesma estatística para todas as atividades. 
Para a variável recursos advindos do PROEXT/MEC, tem-se uma média de recursos recebidos de $R \$ 807.122,27$ com desvio padrão de $R \$ 914.430,78$, mostrando uma dispersão entre as UFs devido à aprovação e contemplação de recursos. O valor máximo recebido foi de $\mathrm{R} \$$ 5.169.360,95 da UFV JM e o mínimo zero de várias UFs.

Já para a variável de ações executadas, a média foi de 1018,22 com desvio padrão de 1791,94, apontando para uma discrepância entre as ações e os benefícios voltados à sociedade, pois o número máximo foi de 12.148 ações da UFSC enquanto o mínimo foi de 6 da UFOPA.

Em relação aos alunos bolsistas, tem-se uma média de 354,99 alunos com desvio padrão de 367,43. A máxima dessa variável foi de 1.962 alunos da UFMG, enquanto algumas UFs não beneficiavam nenhum aluno com bolsa.

Por fim, têm-se os programas e projetos aprovados e contemplados pelo PROEXT/MEC, com média de 6,58 e desvio padrão de 7,3, apresentando uma maior dispersão entre as UFs. O número máximo foi de 32 da UFMG e algumas não tiveram nenhum projeto aprovado ou contemplado.

\section{Tabela 6}

Estatística Descritiva das Variáveis de Extensão

\begin{tabular}{llllll}
\hline Estatística & PROF & RPRO & AEXE & AB & PPPROEXT \\
Média & 1429,46 & 807122,27 & 1018,22 & 354,99 & 6,58 \\
Desvio Padrão & 983,71 & 914430,78 & 1791,94 & 367,43 & 7,30 \\
Máxima & 4126,00 & 5169360,95 & 12148,00 & 1962,00 & 32,00 \\
Mínima & 254,00 & 0,00 & 6,00 & 0,00 & 0,00 \\
\hline Fon
\end{tabular}

Fonte: Elaboração própria (2019).

Diante disso, observa-se, para essa atividade, que as variáveis são as que mais apresentam dispersão, reforçando a ideia de que as atividades de extensão merecem atenção tanto em relação a seu desenvolvimento quanto ao seu acompanhamento pelos órgãos superiores e pela sociedade.

\subsection{Resultados dos Níveis de Eficiência Relativa}

A primeira análise está relacionada à eficiência relativa nas atividades de ensino, conforme apresentado na Tabela 7. 
Tabela 7

Eficiência em atividades de ensino

\begin{tabular}{|c|c|c|c|c|c|}
\hline \multicolumn{6}{|c|}{ ENSINO } \\
\hline DMU & 2013 & 2014 & 2015 & 2016 & 2017 \\
\hline UFBA & 0,925155 & 0,863185 & 0,916086 & 1,000000 & 0,983961 \\
\hline UNIFAL-MG & 0,962835 & 0,902772 & 0,993641 & 0,982029 & 1,000000 \\
\hline UFCSPA & 1,000000 & 1,000000 & 1,000000 & 1,000000 & 1,000000 \\
\hline UFG & 0,945537 & 0,869036 & 0,953743 & 0,917936 & 1,000000 \\
\hline UNIFEI & 1,000000 & 0,905797 & 0,962001 & 1,000000 & 1,000000 \\
\hline UFJF & 1,000000 & 0,990197 & 0,997805 & 1,000000 & 0,979048 \\
\hline UFLA & 1,000000 & 1,000000 & 0,990491 & 0,983768 & 1,000000 \\
\hline UFMT & 1,000000 & 0,845809 & 0,965158 & 1,000000 & 0,906125 \\
\hline UFMS & 0,853388 & 0,786349 & 0,797385 & 0,818331 & 0,818063 \\
\hline UFMG & 1,000000 & 1,000000 & 1,000000 & 1,000000 & 1,000000 \\
\hline UFPE & 0,902446 & 0,888178 & 0,896057 & 0,903914 & 0,902201 \\
\hline UNIR & 0,763417 & 0,677736 & 0,742390 & 0,792896 & 0,696670 \\
\hline UFRR & 1,000000 & 0,808342 & 0,889680 & 1,000000 & 0,852224 \\
\hline UFSC & 0,958865 & 0,989805 & 0,977708 & 0,981836 & 0,995818 \\
\hline UFSM & 0,964134 & 0,955475 & 0,942152 & 0,991473 & 0,975895 \\
\hline UFSJ & 0,991572 & 0,935016 & 1,000000 & 1,000000 & 1,000000 \\
\hline UFU & 0,993838 & 0,926355 & 1,000000 & 0,968242 & 0,984252 \\
\hline UFV & 1,000000 & 1,000000 & 1,000000 & 1,000000 & 1,000000 \\
\hline UFABC & 1,000000 & 1,000000 & 1,000000 & 1,000000 & 1,000000 \\
\hline UFAC & 0,789204 & 0,929282 & 0,876732 & 0,826720 & 0,840901 \\
\hline UFAM & 0,797957 & 0,762137 & 1,000000 & 0,912575 & 0,849185 \\
\hline UFES & 0,916003 & 0,887548 & 0,895576 & 0,984931 & 0,944555 \\
\hline UNIRIO & 1,000000 & 1,000000 & 0,901226 & 1,000000 & 0,971817 \\
\hline UFOPA & 1,000000 & 1,000000 & 1,000000 & 1,000000 & 1,000000 \\
\hline UNIPAMPA & 1,000000 & 0,866101 & 0,912742 & 1,000000 & 0,921234 \\
\hline UFPR & 0,999700 & 0,981065 & 1,000000 & 1,000000 & 1,000000 \\
\hline UFRB & 0,849618 & 1,000000 & 1,000000 & 1,000000 & 0,997407 \\
\hline UFRJ & 1,000000 & 1,000000 & 1,000000 & 1,000000 & 1,000000 \\
\hline FURG & 0,804311 & 0,791640 & 0,803600 & 0,814863 & 0,860067 \\
\hline UFRGS & 1,000000 & 1,000000 & 1,000000 & 1,000000 & 1,000000 \\
\hline UNIVASF & 1,000000 & 0,883158 & 1,000000 & 0,941442 & 0,926698 \\
\hline UFVJM & 1,000000 & 1,000000 & 1,000000 & 1,000000 & 1,000000 \\
\hline UFRA & 1,000000 & 1,000000 & 1,000000 & 1,000000 & 1,000000 \\
\hline UFRRJ & 1,000000 & 0,921319 & 1,000000 & 1,000000 & 0,950751 \\
\hline
\end{tabular}

Pode-se perceber que nove universidades se mantiveram eficientes ao longo do período de análise, são elas: UFCSPA, UFMG, UFV, UFABC, UFOPA, UFRJ, UFRGS, UFVJM e UFRA. No ano de 2013, 18 UFs foram consideradas eficientes, 12 em 2014, 16 em 2015, 20 em 2016 e 15 em 2017. Além disso, a UFMS, a UFPE, a UNIR, a UFSC, a UFSM, a UFAC, a UFES e a FURG não apresentaram eficiência máxima em nenhum dos anos.

Por meio da Tabela 8, analisou-se a média aritmética simples da eficiência relativa das UFs. Observa-se que ela reduz de 2013 para 2014, aumentando aí o desvio padrão; de 2014 até 2016 a média volta a subir, reduzindo assim o desvio padrão; já de 2016 a 2017 ela volta a cair, aumentando o desvio. A média entre os anos foi de 0,949272, com um desvio padrão de 0,072461, apresentando a pior média no ano de 2017. Em todos os anos o nível de eficiência chegou ao máximo, sendo que o mínimo foi no ano de 2014 , com 0,677736 referente a UNIR. A média 
dos menores níveis foi de 0,734622. Pode-se observar ainda que $25 \%$ das UFs apresentaram eficiência menor que 0,930250 em 2013, abaixando para 0,872567 em 2014; em 2015 o nível desse quartil aumenta para 0,913578 e, em 2016, chega a seu melhor nível, de 0,971640, ficando, em 2017, com 0,9226. Vale ressaltar que das 34 UFs estudadas, em todos os anos, o grupo do terceiro quartil $25 \%$ das melhores UFs) ficou com o nível de eficiência igual a 100\%. Além disso, observa-se que a mediana se manteve em 100\% em 2013 e 2016, tendo a pior mediana no ano de 2013.

\section{Tabela 8}

Estatística descritiva do nível de eficiência em atividades de ensino

\begin{tabular}{l|c|c|c|c|c|c}
\hline Estatística & $\mathbf{2 0 1 3}$ & $\mathbf{2 0 1 4}$ & $\mathbf{2 0 1 5}$ & $\mathbf{2 0 1 6}$ & $\mathbf{2 0 1 7}$ & Nível Geral \\
\hline Média & 0,953470 & 0,922538 & 0,953358 & 0,965322 & 0,951673 & 0,949272 \\
\hline Desvio Padrão & 0,073779 & 0,085333 & 0,068376 & 0,062420 & 0,072400 & 0,072461 \\
\hline Máximo & 1,000000 & 1,000000 & 1,000000 & 1,000000 & 1,000000 & 1,000000 \\
\hline Mínimo & 0,763417 & 0,677736 & 0,742390 & 0,792896 & 0,696670 & 0,734622 \\
\hline 1 Quartil & 0,930250 & 0,872567 & 0,913578 & 0,971640 & 0,922600 & 0,922127 \\
\hline Mediana & 1,000000 & 0,932149 & 0,995723 & 1,000000 & 0,990035 & 0,983581 \\
\hline 3 Quartil & 1,000000 & 1,000000 & 1,000000 & 1,000000 & 1,000000 & 1,000000 \\
\hline
\end{tabular}

Fonte: Elaboração própria (2019).

Dessa forma, nota-se que o pior ano em relação às atividades de ensino foi 2014 e o melhor ano foi 2016 . Esses resultados vão ao encontro de Toledo (2017), que afirmou que em 2014 as UFs começaram a sofrer com os cortes universitários advindos do Governo, dificultando até mesmo algumas atividades rotineiras das instituições.

Para a análise, foram considerados os pesos de cada variável, sendo que, em relação ao input, a variável de maior peso em 2013, 2016 e 2017 foi a relação A/P, já em 2014 e 2015 passou a ser PROF. Os maiores pesos de outputs foi de AGE para os anos de 2013, 2015, 2016 e 2017, sendo que, para 2014, foi o IGC, conforme apresentado na Tabela 9. Esses achados corroboram com os apontados por Nuintin (2014), que considerou as variáveis A/P e AGE como as variáveis de maiores pesos em sua pesquisa.

Tabela 9

Pesos das variáveis das atividades de ensino

\begin{tabular}{|c|c|c|c|c|c|c|}
\hline \multicolumn{7}{|c|}{ ENSINO } \\
\hline Pesos & $\operatorname{cg}\{1\}$ & prof \{\}$\}$ & ap $\{1\}$ & age $\{0\}$ & tsg $\{0\}$ & $\operatorname{igc}\{0\}$ \\
\hline 2013 & 0,07 & 0,43 & 0,50 & 0,60 & 0,11 & 0,29 \\
\hline 2014 & 0,06 & 0,57 & 0,37 & 0,38 & 0,12 & 0,50 \\
\hline 2015 & 0,05 & 0,51 & 0,44 & 0,58 & 0,05 & 0,38 \\
\hline 2016 & 0,09 & 0,41 & 0,49 & 0,57 & 0,13 & 0,31 \\
\hline 2017 & 0,12 & 0,41 & 0,47 & 0,47 & 0,08 & 0,45 \\
\hline
\end{tabular}

Fonte: Elaboração própria (2019).

Se tratando somente das UFs que não atingiram a eficiência, considera-se que essas universidades possuem um nível de eficiência bem próximo às universidades consideradas benchmarks (que possuem as melhores práticas), com uma média do nível de eficiência ao longo dos anos de 0,904522, apresentando assim um bom resultado para essa atividade. Para o ano de 2013, 
a média foi de 0,901124, com 16 UFs. Em 2014 foi o ano que apresentou mais dificuldades para as UFs, pois a média reduziu para 0,880287 e 22 UFs não atingiram a eficiência de $100 \%$. Nesse ano a UNIR apresentou também o pior nível de eficiência, chegando a 0,677736. Já em 2015 a média subiu de 0,911898 com 18 UFs; em 2016 chegou a 0,915783 com 14 UFs (considerado o melhor ano para a atividade analisada), fechando 2017 com 19 UFs e com a média de 0,913520.

Já em relação à eficiência nas atividades de pesquisa, pode-se observar, conforme a Tabela 10, que somente nove universidades apresentam-se eficientes ao longo do período analisado, são elas: UFCSPA, UFLA, UFMG, UFRR, UNIRIO, UFOPA, UFPR, FURG e UFRGS. No ano de 2013, 19 UFs foram consideradas eficientes, 17 em 2014, 17 em 2015, 20 em 2016 e 19 em 2017. Além disso, nota-se que a UNIFAL, a UFG, a UFMT, a UFPE, a UFSC, a UFABC e a UFES mostraram-se com baixa eficiência nos períodos analisados.

Tabela 10

Eficiência em atividades de pesquisa

\begin{tabular}{|c|c|c|c|c|c|}
\hline \multicolumn{6}{|c|}{ PESQUISA } \\
\hline DMU & 2013 & 2014 & 2015 & 2016 & 2017 \\
\hline UFBA & 1,000000 & 0,961076 & 0,831808 & 0,955840 & 0,969274 \\
\hline UNIFAL-MG & 0,919879 & 0,837802 & 0,883704 & 0,969462 & 0,888257 \\
\hline UFCSPA & 1,000000 & 1,000000 & 1,000000 & 1,000000 & 1,000000 \\
\hline UFG & 0,947149 & 0,997208 & 0,905633 & 0,993443 & 0,919794 \\
\hline UNIFEI & 1,000000 & 0,916842 & 1,000000 & 1,000000 & 1,000000 \\
\hline UFJF & 1,000000 & 0,754205 & 0,876194 & 0,883236 & 0,940911 \\
\hline UFLA & 1,000000 & 1,000000 & 1,000000 & 1,000000 & 1,000000 \\
\hline UFMT & 0,915332 & 0,747105 & 0,800576 & 0,880514 & 0,913325 \\
\hline UFMS & 0,91 & 0,827130 & 0,998901 & 0,820345 & 1,000000 \\
\hline UFMG & 1,00 & 1,000000 & 1,000000 & 1,000000 & 1,000000 \\
\hline UFPE & 0,90 & 0,907029 & 0,973710 & 0,975991 & 0,922084 \\
\hline UNIR & 0,99 & 1,000000 & 0,866852 & 0,973331 & 1,000000 \\
\hline UFRR & 1,00 & 1,000000 & 1,000000 & 1,000000 & 1,000000 \\
\hline UFSC & 0,99 & 0,921829 & 0,899604 & 0,897827 & 0,959601 \\
\hline UFSM & 0,92 & 0,885818 & 1,000000 & 0,913159 & 0,965065 \\
\hline UFSJ & 0,89 & 0,809389 & 0,957671 & 1,000000 & 1,000000 \\
\hline UFU & 1,00 & 0,959693 & 0,895977 & 0,972006 & 1,00 \\
\hline UFV & 1,000000 & 0,954836 & 0,987362 & 1,000000 & 1,000000 \\
\hline UFABC & 0,920895 & 0,919709 & 0,906454 & 0,955932 & 0,951294 \\
\hline UFAC & 1,000000 & 1,000000 & 1,000000 & 1,000000 & 0,850702 \\
\hline UFAM & 1,000000 & 1,000000 & 1,000000 & 1,000000 & 0,950480 \\
\hline UFES & 0,850123 & 0,765462 & 0,846167 & 0,911577 & 0,963020 \\
\hline UNIRIO & 1,000000 & 1,000000 & 1,000000 & 1,000000 & 1,000000 \\
\hline UFOPA & 1,000000 & 1,000000 & 1,000000 & 1,000000 & 1,000000 \\
\hline UNIPAMPA & 1,000000 & 1,000000 & 1,000000 & 1,000000 & 0,892857 \\
\hline UFPR & 1,000000 & 1,000000 & 1,000000 & 1,000000 & 1,000000 \\
\hline UFRB & 1,000000 & 1,000000 & 1,000000 & 1,000000 & 0,916506 \\
\hline UFRJ & 0,990393 & 1,000000 & 1,000000 & 1,000000 & 1,000000 \\
\hline FURG & 1,000000 & 1,000000 & 1,000000 & 1,000000 & 1,000000 \\
\hline UFRGS & 1,000000 & 1,000000 & 1,000000 & 1,000000 & 1,000000 \\
\hline UNIVASF & 0,908100 & 1,000000 & 1,000000 & 1,000000 & 1,000000 \\
\hline UFVJM & 0,983671 & 0,985222 & 0,978665 & 1,000000 & 0,937910 \\
\hline UFRA & 1,000000 & 1,000000 & 0,988435 & 1,000000 & 1,000000 \\
\hline UFRRJ & 0,979912 & 0,690894 & 0,766989 & 0,834168 & 1,000000 \\
\hline
\end{tabular}

Fonte: Elaboração própria (2019). 
Por meio da Tabela 11, analisou-se a média aritmética simples do nível de eficiência relativa das UFs em atividades de pesquisa. Observa-se que ela reduz de 2013 para 2014 (sendo considerada a pior média, 0,936507), voltando a aumentar gradativamente até 2017, apresentando, em 2014, um maior desvio padrão da amostra. A média entre os anos foi de 0,959532 com um desvio padrão de 0,059318. Em todos os anos, o nível de eficiência chegou ao máximo, sendo que o mínimo foi no ano de 2014, com 0,690894 da UFRRJ. A média dos menores níveis foi de 0,795810. Pode-se observar ainda que $25 \%$ das UFs apresentaram eficiência menor que 0,929308 em 2013, reduzindo para 0,909483 em 2014, chegando, em 2015, a 0,901111. Já em 2016, o nível desse quartil aumenta para 0,959314 - chegando a seu melhor nível - e voltando a cair em 2017 para 0,943303, mantendo uma média entre os anos de 0,928504. Em relação ao grupo do terceiro quartil, que abrange $25 \%$ das melhores UFs, observa-se que em todos os anos essas instituições ficaram com o nível de eficiência igual a 100\%. Além disso, verifica-se que a mediana só não foi 1,0 em 2014 e 2015, apesar de ficar bem próxima da eficiência total.

Dessa forma, nota-se que o pior ano em relação às atividades de pesquisa foi 2014 e o melhor ano foi 2017. Moreno (2018) menciona que as universidades federais tiveram em 2017 o menor repasse de verbas, operando com $90 \%$ de perdas em relação a 2013, apontando assim que as UFs sofreram o impacto em 2014, mas aos poucos conseguiram trabalhar com a situação, de modo a apresentar um melhor resultado com menores gastos.

\section{Tabela 11}

Estatística descritiva do nível de eficiência em atividades de pesquisa

\begin{tabular}{l|c|c|c|c|c|c}
\hline Estatística & $\mathbf{2 0 1 3}$ & $\mathbf{2 0 1 4}$ & $\mathbf{2 0 1 5}$ & $\mathbf{2 0 1 6}$ & $\mathbf{2 0 1 7}$ & Nível Geral \\
\hline Média & 0,971664 & 0,936507 & 0,951903 & 0,968730 & 0,968855 & 0,959532 \\
\hline Desvio Padrão & 0,043109 & 0,091609 & 0,068697 & 0,051399 & 0,041778 & 0,059318 \\
\hline Máximo & 1,000000 & 1,000000 & 1,000000 & 1,000000 & 1,000000 & 1,000000 \\
\hline Mínimo & 0,850123 & 0,690894 & 0,766989 & 0,820345 & 0,850702 & 0,795810 \\
\hline 1 Quartil & 0,929308 & 0,909483 & 0,901111 & 0,959314 & 0,943303 & 0,928504 \\
\hline Mediana & 1,000000 & 0,998604 & 0,999451 & 1,000000 & 1,000000 & 0,999611 \\
\hline 3 Quartil & 1,000000 & 1,000000 & 1,000000 & 1,000000 & 1,000000 & 1,000000 \\
\hline
\end{tabular}

Fonte: Elaboração própria (2019).

A fim de complementar a análise, foram observados os pesos de cada variável, sendo que, em relação ao input, a variável de maior peso em todos os anos foi IQCD e a variável de outputs foi CCPG em todos os anos também, conforme apresentado na Tabela 12. Nuintin (2014) também apresenta O IQCD como variável influenciadora na eficiência das UFs. Costa et al. (2012) ainda apresentaram que IQCD e o CCPG representaram fatores de ineficiência das IFES. 
Tabela 12

Pesos das variáveis das atividades de pesquisa

\begin{tabular}{c|r|r|r|r|r|r|r|r}
\hline \multicolumn{10}{c}{ PESQUISA } \\
\hline Pesos & css\{l\} & prof\{l\} & fomcc $\{\mid\}$ & iqcd $\{1\}$ & dp $\{0\}$ & ccpg\{O\} & gepg\{O\} & hindex\{O\} \\
\hline $\mathbf{2 0 1 3}$ & 0,09 & 0,11 & 0,17 & $\mathbf{0 , 6 2}$ & 0,16 & $\mathbf{0 , 4 9}$ & 0,20 & 0,14 \\
\hline $\mathbf{2 0 1 4}$ & 0,09 & 0,16 & 0,29 & $\mathbf{0 , 4 6}$ & 0,15 & $\mathbf{0 , 3 5}$ & 0,20 & 0,30 \\
\hline $\mathbf{2 0 1 5}$ & 0,07 & 0,20 & 0,26 & $\mathbf{0 , 4 7}$ & 0,23 & $\mathbf{0 , 3 1}$ & 0,25 & 0,20 \\
\hline $\mathbf{2 0 1 6}$ & 0,07 & 0,21 & 0,25 & $\mathbf{0 , 4 7}$ & 0,22 & $\mathbf{0 , 3 5}$ & 0,25 & 0,18 \\
\hline $\mathbf{2 0 1 7}$ & 0,08 & 0,16 & 0,18 & $\mathbf{0 , 5 8}$ & 0,19 & $\mathbf{0 , 5 1}$ & 0,19 & 0,12 \\
\hline
\end{tabular}

Fonte: Elaboração própria (2019).

Ao analisar somente as UFs que não atingiram a eficiência, considera-se que essas universidades possuem um nível de eficiência médio de 0,913211 em relação às universidades consideradas benchmarks, apresentando, portanto, um bom resultado para essa atividade. Para o ano de 2013, a média foi de 0,935772 com 15 UFs, em 2014, a média reduziu para 0,83015 com 17 UFs, mostrando-se como o ano com mais UFs que não atingiram a eficiência máxima e com o menor nível. Já em 2015 a média subiu para 0,903806 com 17 UFs, em 2016 foi para 0,924059 com 14 UFs, fechando 2017 com 15 UFs e com a média de 0,929405 (considerado o melhor ano para a atividade analisada).

Por fim, os níveis de eficiência nas atividades de extensão são observados na Tabela 13. Os resultados apontam que as universidades têm mais dificuldades para se manterem eficientes nesse quesito, visto que apenas três universidades são consideradas com eficiência máxima em relação ao grupo de análise nos anos de 2013 a 2017, são elas: UFCSPA, UFMG e UFSC. No ano de 2013, 12 UFs foram consideradas com eficiência máxima, 18, em 2014, 19, em 2015, 15, em 2016 e somente 4, em 2017. Vale ainda ressaltar que a UFBA, a UFMT, a UFMS, a UFPE, a UNIR, a UFRR, a UFSM, a UFAM e a UFES foram às únicas universidades que em nenhum dos anos de análise obtiveram eficiência máxima. 
Tabela 13

Eficiência em atividades de extensão

\begin{tabular}{l|c|c|c|c|c}
\hline \multicolumn{7}{c}{ DXIENSÃO } & $\mathbf{2 0 1 3}$ & $\mathbf{2 0 1 4}$ & $\mathbf{2 0 1 5}$ & $\mathbf{2 0 1 6}$ & $\mathbf{2 0 1 7}$ \\
\hline UFBA & 0,698861 & 0,714957 & 0,585720 & 0,511326 & 0,211569 \\
\hline UNIFAL-MG & 0,825355 & 1,000000 & 0,954107 & 1,000000 & 0,652273 \\
\hline UFCSPA & 1,000000 & 1,000000 & 1,000000 & 1,000000 & 1,000000 \\
\hline UFG & 0,900576 & 0,876949 & 1,000000 & 1,000000 & 0,158446 \\
\hline UNIFEI & 0,771069 & 1,000000 & 1,000000 & 1,000000 & 0,244942 \\
\hline UFJF & 0,898634 & 1,000000 & 1,000000 & 0,882379 & 0,621852 \\
\hline UFLA & 1,000000 & 1,000000 & 0,764234 & 1,000000 & 0,722335 \\
\hline UFMT & 0,765990 & 0,708209 & 0,689941 & 0,553465 & 0,339443 \\
\hline UFMS & 0,977231 & 0,844044 & 0,888257 & 0,949487 & 0,344092 \\
\hline UFMG & 1,000000 & 1,000000 & 1,000000 & 1,000000 & 1,000000 \\
\hline UFPE & 0,713318 & 0,853558 & 0,721917 & 0,400064 & 0,198942 \\
\hline UNIR & 0,710833 & 0,621075 & 0,618353 & 0,160408 & 0,185065 \\
\hline UFRR & 0,734376 & 0,322843 & 0,856751 & 0,401091 & 0,292629 \\
\hline UFSC & 1,000000 & 1,000000 & 1,000000 & 1,000000 & 1,000000 \\
\hline UFSM & 0,720929 & 0,983811 & 0,771545 & 0,848320 & 0,343725 \\
\hline UFSJ & 0,945984 & 1,000000 & 1,000000 & 1,000000 & 0,708567 \\
\hline UFU & 0,846740 & 0,967960 & 1,000000 & 0,827883 & 0,405055 \\
\hline UFV & 1,000000 & 1,000000 & 1,000000 & 1,000000 & 0,809127 \\
\hline UFABC & 1,000000 & 1,000000 & 1,000000 & 0,800897 & 0,344542 \\
\hline UFAC & 0,769941 & 0,804728 & 1,000000 & 1,000000 & 1,000000 \\
\hline UFAM & 0,733245 & 0,814169 & 0,705069 & 0,434141 & 0,155239 \\
\hline UFES & 0,898715 & 0,879471 & 0,851281 & 0,583124 & 0,333467 \\
\hline UNIRIO & 0,711541 & 1,000000 & 1,000000 & 1,000000 & 0,690417 \\
\hline UFOPA & 1,000000 & 0,908299 & 1,000000 & 1,000000 & 0,857192 \\
\hline UNIPAMPA & 0,754205 & 1,000000 & 0,719166 & 0,799361 & 0,286747 \\
\hline UFPR & 0,910581 & 1,000000 & 0,848680 & 0,871308 & 0,413890 \\
\hline UFRB & 1,000000 & 1,000000 & 0,726850 & 0,312607 & 0,264557 \\
\hline UFRJ & 0,960430 & 0,931034 & 1,000000 & 0,868961 & 0,810504 \\
\hline FURG & 1,000000 & 1,000000 & 0,807363 & 1,000000 & 0,175177 \\
\hline UFRGS & 0,869036 & 0,671194 & 1,000000 & 1,000000 & 0,476872 \\
\hline UNIVASF & 0,752785 & 0,652183 & 1,000000 & 0,776036 & 0,267380 \\
\hline UFVJM & 1,000000 & 1,000000 & 1,000000 & 0,540132 & 0,238812 \\
\hline UFRA & 1,000000 & 1,000000 & 1,000000 & 1,000000 & 0,301814 \\
\hline UFRRJ & 1,000000 & 1,000000 & 1,000000 & 0,606281 & 0,652188 \\
\hline
\end{tabular}

Fonte: Elaboração própria (2019).

Por meio da Tabela 14, analisou-se a média aritmética simples do nível de eficiência relativa das UFs em relação às atividades de extensão. Observa-se que ela aumenta de 2013 até 2015, e, posteriormente a isso, passa a diminuir até 2017, apresentando, em 2017, o pior nível com um maior desvio padrão da amostra. A média entre os anos foi de 0,791578 com um desvio padrão de 0,187903. Em todos os anos, o nível de eficiência chegou ao máximo, sendo que o mínimo foi no ano de 2017 com 0,155239 da UFAM. A média dos menores níveis foi de 0,384614. Pode-se observar ainda que $25 \%$ das UFs apresentaram eficiência menor que 0,757151 em 2013, aumentando para 0,846423 em 2014, voltando a reduzir em 2015 para 0,7805; diminuindo em 2016 para 0,588914 e 2017 para 0,265263 (chegando a seu pior nível), mantendo uma média entre os anos de 0,647650. Em relação ao grupo do terceiro quartil, considerando $25 \%$ das melhores UFs, observa-se que em todos os anos essas UFs ficaram com o nível de eficiência igual 
a 100\%, exceto em 2017, em que tiveram um nível de 0,704029. Além disso, observa-se que a mediana só foi 1,0 em 2014 e 2015, tendo a pior mediana em 2017, de 0,344317. Dessa forma, nota-se que o pior ano em relação às atividades de extensão foi 2017 e o melhor 2014. Essa situação pode ser reflexo da queda de repasses advindos do PROEXT/MEC, que, em 2015 e 2016, foram reduzidos e, em 2017, não foi disponibilizado nenhum valor (PROEXT/ MEC, 2018).

Tabela 14

Estatística descritiva do nível de eficiência em atividades de extensão

\begin{tabular}{l|c|c|c|c|c|c}
\hline Estatística & $\mathbf{2 0 1 3}$ & $\mathbf{2 0 1 4}$ & $\mathbf{2 0 1 5}$ & $\mathbf{2 0 1 6}$ & $\mathbf{2 0 1 7}$ & Nível Geral \\
\hline Média & 0,878540 & 0,898661 & 0,897330 & 0,797861 & 0,485496 & 0,791578 \\
\hline Desvio Padrão & 0,117279 & 0,156766 & 0,134596 & 0,248527 & 0,282349 & 0,187903 \\
\hline Máximo & 1,000000 & 1,000000 & 1,000000 & 1,000000 & 1,000000 & 1,000000 \\
\hline Mínimo & 0,698861 & 0,322843 & 0,585720 & 0,160408 & 0,155239 & 0,384614 \\
\hline 1 Quartil & 0,757151 & 0,846423 & 0,780500 & 0,588914 & 0,265263 & 0,647650 \\
\hline Mediana & 0,899646 & 1,000000 & 1,000000 & 0,876843 & 0,344317 & 0,824161 \\
\hline 3 Quartil & 1,000000 & 1,000000 & 1,000000 & 1,000000 & 0,704029 & 0,940806 \\
\hline
\end{tabular}

Fonte: Elaboração própria (2019).

Observa-se por meio da Tabela 15 que a variável de input de maior peso, de 2013 a 2015, foi RPRO e em relação aos outputs, de 2013 a 2016, foi PPPROEXT e, em 2017, passou a ser $A B$.

\section{Tabela 15}

Pesos das variáveis das atividades de extensão

\begin{tabular}{c|r|r|r|r|r}
\hline \multicolumn{7}{|c}{ EXIENSÃO } \\
\hline Pesos & prof\{l\} & rpro\{l\} & aexe $\{0\}$ & \multicolumn{1}{c}{ ab $\{0\}$} & ppproext\{O\} \\
\hline $\mathbf{2 0 1 3}$ & 0,32 & $\mathbf{0 , 6 8}$ & 0,09 & 0,18 & $\mathbf{0 , 7 4}$ \\
\hline $\mathbf{2 0 1 4}$ & 0,02 & $\mathbf{0 , 9 8}$ & 0,00 & 0,00 & $\mathbf{1 , 0 0}$ \\
\hline $\mathbf{2 0 1 5}$ & 0,39 & $\mathbf{0 , 6 1}$ & 0,09 & 0,23 & $\mathbf{0 , 6 8}$ \\
\hline $\mathbf{2 0 1 6}$ & $\mathbf{0 , 5 8}$ & 0,42 & 0,14 & 0,23 & $\mathbf{0 , 6 3}$ \\
\hline $\mathbf{2 0 1 7}$ & $\mathbf{1 , 0 0}$ & 0,00 & 0,39 & $\mathbf{0 , 6 1}$ & 0,00 \\
\hline
\end{tabular}

Fonte: Elaboração própria (2019).

Ao analisar somente as UFs que não atingiram a eficiência máxima, tem-se a média do nível de eficiência relativa ao longo do período analisado de 0,683880, mostrando uma queda constante desde 2013. Apesar do nível de eficiência cair de 0,812290 em 2013 para 0,784655 em 2014, o número de UFs diminuiu de 22 para 16. Em 2015, a média reduz para 0,767282, caindo para 15 UFs. Em 2016 e 2017, essa situação piora, apresentando uma média de 0,638277 em 2016, chegando a 0,416895 em 2017, passando de 19 para 30 UFs, respectivamente. Apontando assim, que 2017 foi o pior ano, reforçando a ideia de que, com a falta de recursos PROEXT/MEC, as UFs não conseguem desenvolver atividades voltadas à sociedade.

Entendendo que o ensino, pesquisa e extensão são consideradas funções pelas quais a missão das universidades se realiza (Brasil, 1988; Ospina, 1990), observa-se, por meio da Tabela 16, que seis UFs cumpriram sua missão com eficiência máxima em 2013, 2014 e 2015, passando para oito em 2016 e caindo para duas em 2017. 
Tabela 16

Universidades com eficiência máxima

\begin{tabular}{c|c|c|c|c}
\hline $\mathbf{2 0 1 3}$ & $\mathbf{2 0 1 4}$ & $\mathbf{2 0 1 5}$ & $\mathbf{2 0 1 6}$ & $\mathbf{2 0 1 7}$ \\
\hline UFCSPA & UFCSPA & UFCSPA & UFCSPA & UFCSPA \\
UFLA & UFLA & UFMG & UFMG & UFMG \\
UFMG & UFMG & UFOPA & UFSJ & \\
UFV & UNIRIO & UFRJ & UFV & \\
UFOPA & UFRB & UFRGS & UNIRIO & \\
UFRA & UFRA & UNIVASF & UFOPA & \\
& & & UFRGS & \\
& & & UFRA & \\
\hline
\end{tabular}

Fonte: Elaboração própria (2019).

Assim, ao analisar todas as atividades em conjunto e em todos os anos compreendidos na análise, as únicas universidades que se mantiveram 100\% eficientes foram a UFCSPA e a UFMG. Ainda nesse contexto, utilizou-se a média aritmética simples dos níveis de eficiência relativa das três dimensões e no período de 2012 a 2017 para classificar as UFs e assim apresentar o ranking referente aos melhores níveis de eficiência relativa, conforme Tabela 17.

Tabela 17

Ranking das Universidades analisadas

\begin{tabular}{lcc}
\hline \hline \multicolumn{1}{c}{ DMU } & MÉDIA & RANKING \\
\hline \hline UFCSPA & 1,000000 & $\mathbf{1}$ \\
UFMG & 1,000000 & $\mathbf{1}$ \\
UFOPA & 0,984366 & $\mathbf{2}$ \\
UFV & 0,983422 & $\mathbf{3}$ \\
UFSC & 0,971874 & $\mathbf{4}$ \\
UFRJ & 0,970755 & $\mathbf{5}$ \\
UFLA & 0,964055 & $\mathbf{6}$ \\
UFRA & 0,952683 & $\mathbf{7}$ \\
UNIRIO & 0,951667 & $\mathbf{8}$ \\
UFSJ & 0,949298 & $\mathbf{9}$ \\
UFPR & 0,935015 & $\mathbf{1 0}$ \\
UFRGS & 0,934473 & $\mathbf{1 1}$ \\
UFJF & 0,921631 & $\mathbf{1 2}$ \\
UNIFEI & 0,920043 & $\mathbf{1 3}$ \\
UFABC & 0,919982 & $\mathbf{1 4}$ \\
UNIFAL & 0,918141 & $\mathbf{1 5}$ \\
UFU & 0,916533 & $\mathbf{1 6}$ \\
\hline \hline
\end{tabular}

\begin{tabular}{ccc}
\hline \hline DMU & MÉDIA & RANKING \\
\hline \hline UFAC & 0,912547 & $\mathbf{1 7}$ \\
UFVJM & 0,910961 & $\mathbf{1 8}$ \\
UFRRJ & 0,893500 & $\mathbf{1 9}$ \\
UFG & 0,892363 & $\mathbf{2 0}$ \\
UFSM & 0,878991 & $\mathbf{2 1}$ \\
UNIPAMPA & 0,876827 & $\mathbf{2 2}$ \\
UNIVASF & 0,873852 & $\mathbf{2 3}$ \\
UFRB & 0,871170 & $\mathbf{2 4}$ \\
FURG & 0,870468 & $\mathbf{2 5}$ \\
UFMS & 0,842729 & $\mathbf{2 6}$ \\
UFES & 0,834068 & $\mathbf{2 7}$ \\
UFRR & 0,810529 & $\mathbf{2 8}$ \\
UFBA & 0,808588 & $\mathbf{2 9}$ \\
UFAM & 0,807613 & $\mathbf{3 0}$ \\
UFPE & 0,804026 & $\mathbf{3 1}$ \\
UFMT & 0,802066 & $\mathbf{3 2}$ \\
UNIR & 0,720092 & $\mathbf{3 3}$ \\
\hline \hline
\end{tabular}

Fonte: Elaboração própria (2019).

Observa-se que a pior média no tripé das atividades é da UNIR, com nível de eficiência relativa de 0,720092, ocupando assim a $33^{\circ}$ colocação (visto que o primeiro lugar é ocupado pela UFCSPA e UFMG). Vale ressaltar que, apesar desta UF apresentar o pior nível dentre as outras, ela possui $72 \%$ de eficiência, valor ainda considerado alto. Esse valor é oriundo de uma média de ensino de 0,734622, seguida de 0,966508 em pesquisa e 0,459147 em extensão. 


\section{CONSIDERAÇÕES FINAIS}

Esta pesquisa teve como objetivo avaliar o nível de eficiência relativa de Universidades Federais brasileiras nas atividades de ensino, pesquisa e extensão de 2013 a 2017. Pode-se observar que as UFs apresentam melhores níveis de eficiência nas atividades de pesquisa, seguido de atividades de ensino e, por fim, atividades de extensão. Apesar do número de UFs com eficiência máxima, em todos os anos, serem nove para as atividades de ensino e pesquisa, a média das que não atingiram eficiência máxima é maior para a pesquisa. Vale destacar, que os melhores níveis de eficiência nas atividades de pesquisa foram em 2017 e para o ensino 2016. Já para as atividades de extensão foi em 2014, enquanto esse ano foi o pior para as atividades de ensino e pesquisa.

Além disso, sabendo que a missão das universidades é realizar atividades de ensino, pesquisa e extensão, observou-se que, conforme os parâmetros do estudo, apenas seis UFs obtiveram eficiência máxima no tripé de atividades em 2013, 2014 e 2015, passando para oito em 2016 e reduzindo para duas em 2017. Apontando que apenas a UFCSPA e a UFMG se mantiveram totalmente eficientes em todas as atividades em conjunto e em todos os anos compreendidos na análise.

Vale ressaltar que a UFCSPA foi a universidade com menor número de cursos de graduação, bem como de cursos stricto senso. Já a UFM foi a que teve maior número de depósitos de patentes, maiores números de bolsistas de extensão e maior número de programas e projetos aprovados e contemplados pelo PROEXT/MEC. O fator influenciador para que elas se apresentassem eficientes foi a otimização dos inputs para maximizar os outputs, principalmente no que tange as variáveis de maior peso. São elas: ensino, aluno/professor e aluno equivalente na graduação; pesquisa, índice de qualificação docente e conceito CAPES/MEC para a Pós-Graduação; e, extensão, recursos oriundos da PROEXT/MEC e número de programas e projetos aprovados e contemplados pela mesma.

Os resultados ainda apontam que para que as UFs melhorem seus resultados elas devem se preocupar em ter um número suficientes de professores, com um alto índice de qualificação, suficientes para ter um bom indicador da relação aluno por professor. O melhor aproveitamento do corpo docente deverá propiciar uma melhor produtividade da UF, a fim de buscar uma melhor eficiência.

Ademais, os gestores deverão buscar maximizar a quantidade aluno equivalente de graduação, uma vez que este avalia a relação entre concluintes e ingressantes, levando em consideração o desempenho do curso, focando aqueles que merecem uma atenção especial. Maximizar este indicador, além de propiciar uma maior eficiência, também trará mais recursos para as UFs, uma vez que ele equivale a $80 \%$ da Matriz de Orçamento de Custeio e Capital (OCC), propiciando assim, mais investimentos em todas as atividades.

Os gestores também deverão se preocupar em aumentar o conceito CAPES/MEC para a Pós-Graduação, buscando com que seus cursos strictu senso tenham boas propostas, um corpo docente altamente qualificado, um corpo discente selecionado, produzindo teses e dissertações de impacto, uma boa produção intelectual e com inserção social. 
Ainda neste sentido, faz-se necessário que as UFs busquem programas de apoio às atividades de extensão, uma vez que os resultados apontam que os recursos oriundos da PROEXT/MEC deverão atender às demandas sociais propostos pelos programas e projetos aprovados e contemplados por ela. Vale ressaltar que a partir de 2017 não tem havido investimentos via PROEXT/MEC, mostrando que para melhorar sua eficiência, as UFs devem beneficiar alunos com bolsas de extensão. Uma vez que a ajuda financeira estimula a interação dos estudantes da universidade com outros setores da sociedade, por meio de atividades que contribuam para a sua formação acadêmica, profissional e para o exercício da cidadania.

Do exposto, acredita-se que este estudo apresenta uma visão geral do nível de eficiência das UFs analisadas no período compreendido entre 2013 e 2017, indicando ainda quais delas cumprem melhor sua missão e dão mais retorno à sociedade. Conclui-se que, a partir dos resultados apresentados, os gestores podem trabalhar de modo que gerenciem melhor seus recursos e disponibilidades, principalmente aqueles que mais impactam na sua produtividade, buscando assim as melhores práticas e melhores resultados.

É importante destacar a importância e o impacto gerado pela redução de verbas governamentais aplicadas às UFs, principalmente após o Reuni (momento de expansão), visto que é por meio dos recursos recebidos que elas podem gerenciar suas atividades, buscando maximizar suas atividades e resultados. Essas dificuldades enfrentadas pelas UFs apontam para uma retração na condição de trabalho e na possibilidade de melhores condições para os alunos e a sociedade em geral. Ademais, por mais que esses recursos têm sido reduzidos ao longo do período, as UFs têm mostrado um bom desempenho em relação ao seu nível de eficiência, apontando o quão são capazes de contribuir para o desenvolvimento socioeconômico.

Além disso, este estudo evidencia que as UFs precisam de um maior controle de suas informações e resultados gerados, principalmente no que tange às atividades de extensão, levando ainda em consideração um maior investimento em tecnologia para tal. Um maior controle permitiria um maior acompanhamento de suas atividades, bem como comparação com outras instituições, possibilitando que estas busquem as melhores práticas de gestão. Ressalta-se que esse foi o motivo que fez com que a pesquisa se restringisse a analisar somente as UFs que disponibilizaram todos os dados necessários para o período escolhido para a análise, uma vez que este é um limitador da metodologia DEA.

Outro ponto a ser destacado é a importância de se padronizar indicadores voltados às atividades de extensão, uma vez que se pode perceber que cada UFs mantém seu próprio controle, algumas mais rígidas outras nem tanto. Ademais, não havendo essa padronização e nem acompanhamento por parte do governo, não é possível analisar o desempenho destas para com a sociedade, sabendo o fortalecimento da relação universidade-sociedade advém do desenvolvimento de ações que possibilitem contribuições aos cidadãos.

Diante da dificuldade encontrada em se obter os dados referentes à extensão universitária, a amostra da análise do estudo se limitou às 34 UFs apresentadas anteriormente, tornando-se assim o delimitador desse estudo. Dessa forma, todas as inferências se referem à eficiência relativa da amostra 
selecionada e neste período, não podendo ser extrapoladas para outras universidades e períodos diferentes.

Assim, sugere-se como pesquisas futuras: a inclusão de novas variáveis ao modelo, principalmente em relação às atividades de extensão, a mensuração da eficiência relativa, considerando o input despesas orçamentárias e output as variáveis do tripé de atividades, a comparação do nível de eficiência de instituições públicas e privadas.

\section{REFERÊNCIAS}

Ahn, T. S. (1987). Efficiency and related issues in higuer education: a data envelopment analysis approach. Tesis Doctoral - University of Texas at Austin, Austin.

Arretche, M. (1999). Tendências no estudo sobre avaliação. In: RICO, E. M. (Org.). Avaliação de políticas sociais: uma questão em debate. São Paulo: Cortez.

Avkiran, N. K. (2001). Investigating technical and scale efficiencies of Australian universities through data envelopment analysis. Socio Economic Planning Sciences, Elsevier, 35(3), 57-80.

Banker, R. D., Charnes, A. \& Cooper, W. W. (1984). Some models for estimation technical and scale inefficiencies in data envelopment analysis. Management Science, Providence, 30 (9), 1078-1092.

Baracho, M. A. P. (2000). A importância da gestão de contas públicas municipais sob as premissas da governance e accountability. Revista Tribunal de Contas de Minas Gerais, Belo Horizonte, 34(1), 129-16.

Barros, R. P; Henriques, R. \& Mendonça, R. (2002). Pelo fim das décadas perdidas: educação e desenvolvimento sustentado no Brasil. Rio de Janeiro: IPEA.

Belloni, J. A. (2000). Uma metodologia de avaliação da eficiência produtiva de universidades federais brasileiras. Tese de Doutorado em Engenharia de Produção - Departamento de Engenharia de Produção e Sistemas, Universidade Federal de Santa Catarina, Florianópolis.

Bertassi, A. L. (2016). Controladoria estratégica governamental aplicada ao poder executivo: uma contribuição teórica. Tese de Doutorado em Administração - Faculdade de Gestão e Negócios, Universidade Metodista de Piracicaba, Piracicaba.

Brasil. Constituição (1988). Constituição da República Federativa do Brasil. São Paulo: Saraiva.

Brasil. (2001). Decreto $n^{\circ} 3.860$, de 9 de julho de 2001. Dispõe sobre a organização do ensino superior, a avaliação de cursos e instituições, e dá outras providências. Brasília. Recuperado em 25 out 2018 de http://www.planalto.gov.br/ccivil_03/decreto/2001/d3860.htm 
Brasil. (2008). Decreto $n^{\circ}$ 6.495, de 30 de junho de 2008. Institui o Programa de Extensão Universitária - PROEXT. Brasília, 2008. Recuperado em 25 out 2018 de http://www.planalto.gov.br/ccivil_03/_Ato2007-

2010/2008/Decreto/D6495.htm

Brasil. (2011). Lei $n^{\circ}$ 12.527, de 18 de Novembro de 2011. Lei de Acesso à Informação. Brasília, 2011. Recuperado em 25 out 2018 de http://www.planalto.gov.br/ccivil_03/_ato201 1-2014/201 1/lei/l12527.htm

Brasil. (2017). Ministério da Educação. Cursos e Instituições. Brasília. Recuperado em 24 set 2017 de http://portal.mec.gov.br/pec-g/cursos-e-instituicoes

Bresser-Pereira L. C. (1999). Reflexões sobre a reforma gerencial brasileira de 1995. Revista do Serviço Público, Brasília, 50 (4), 5-29.

Cândido Junior, O.J. (2001). Os gastos públicos no Brasil são produtivos? Planejamento e políticas públicas. Brasília: IPEA, n. 23, jun. 2001. Recuperado em $31 \quad$ maio 2018 de https://www.ipea.gov.br/ppp/index.php/PPP/article/viewFile/77/88

Casa Nova, S. P. C. (2002). Utilização da Análise por Envoltória de Dados (DEA) na análise de demonstrações contábeis. Tese de Doutorado em Contabilidade e Controladoria - Faculdade de Economia, Administração e Contabilidade, Universidade de São Paulo, São Paulo.

Castano, M. C. N. \& Cabanda, E. C. (2007). Performance evaluation of the efficiency of Philippine Private Higher Educational Institutions: application of frontier approaches. International Transactions In Operational Research, WileyBlackwell, 14, 431-444.

Castro, L. M. C. (2004). A universidade, a extensão universitária e a produção de conhecimentos emancipadores. In: REUNIÃO ANUAL DA ANPED, 27, Caxambu. Anais... Caxambu: ANPEd. Recuperado em 31 maio 2018 de http://27reuniao.anped.org.br/gt1 1/ †1 111.pdf

Charnes, A.; et al. (1994). Data Envolopment Analysis: theory, methodology and applications. USA, Kluwer Academic Publishers.

Charnes, A., Cooper, W. W. \& Rhodes, E. (1978). Measuring the efficiency of decision-making units. European Journal of Operational Research, Amsterdam, 2(6), 429-444.

Chaves, D. C. R. (2009). A universidade empreendedora do séc. XXI: o papel estratégico da propriedade industrial. Dissertação de Mestrado em Sociologia - Faculdade de Economia da Universidade de Coimbra, Coimbra, Portugal.

Chen, T.,Yeh, T. \& Chung, M. (2012). Financial performance of township governments and its four budget cycles. African Journal of Business Management, 6 (2), 530-537.

Coelli, T., Rao, D., O'Donnell, C. \& Battese, G. (2005). An introduction to eficiency and productivity analysis. 2. ed. Berlin: Springer.Colin, E. C. (2007). Pesquisa 
Operacional: 170 aplicações em estratégia, finanças, logística, produção, marketing e vendas. Rio de Janeiro: LTC.

Cook, W. D. \& Zhu, J. (2008). Data envelopment analysis: modeling operational processes and measuring productivity. Dordrecth: Kluwer Academic Publishers.

Corbucci, P. R. (2000). As universidades federais: gasto, desempenho, eficiência e produtividade. Brasilia: Ipea.

Corbucci, P. R. (2007). Desafios da educação superior e desenvolvimento no Brasil. Brasilia: IPEA.

Costa, E. M., Ramos, F. S. \& Souza, H. R. (2010). Mensuração de Eficiência Produtiva das Instituições Federais de Ensino Superior (Ifes). Finanças públicas - XV Prêmio Tesouro Nacional. Recuperado em 10 out 2015 de http://www3.tesouro.fazenda.gov.br/Premio_TN/XVPremio/qualidade/2quali dadeXVPTN/Tema_2_2.pdf

Costas, R. \& Bordons, M. (2007). The h-index: Advantages, limitations and its relation with other bibliometric indicators at the micro level. Journal of Informetrics, Amsterdam, 1, 193-203.

Cruz, I. B. (2004). A Experiência do TCU com Indicadores de Gestão das IFES. Seminário Diálogo Público - TCU: Braślia.

Curi, M. A. (2015). Eficiência de universidades federais no uso de recursos renováveis. Tese de Doutorado em Administração - Universidade Federal de Lavras, Lavras.

Daraio, C. \& Simar, L. (2007). Advanced Robust and Nonparametric Methods in Efficiency Analysis: methodology and applications. New York: Springer Science \& Business Media.

Debreu, G. (1951). The coefficient of resource utilization. Econometrica, New York, $19(3), 273-292$.

Dufrechou, P. A. (2016). The efficiency of public education spending in Latin America: A comparison to high-income countries. International Journal of Educational Development, Elservier, 49, 188-203.

Farrell, M. J. (1957). The measurement of productive efficiency. Journal of the Royal Statistical Society, Londres, 120(3), 253-290, A, III.

Ferreira, C. M. C. \& Gomes, A. P. (2012). Introdução à análise envoltória de dados: teoria, modelos e aplicações. Viçosa: UFV.

Fuentes, R., Fuster, B. \& Lillo-Bañuls, A. (2016). A three-stage DEA model to evaluate learning-teaching technical efficiency: Key performance indicators and contextual variables. Expert Systems With Applications, Elservier, 48, 89-99. 
Golany, B. \& Roll, Y. (1989). An application procedure for DEA. Omega International Journal of Management Science, Elservier, 17(3), 237-250.

Gomes, J. A.V. (2016). Eficiência do gasto público em educação superior: um estudo sobre as universidades federais do estado de Minas Gerais. Dissertação do Programa de Pós-Graduação em Administração Pública em Rede Nacional (PROFIAP) - Universidade Federal de Viçosa, Viçosa, 2016.

Gomes, A. P. \& Baptista, A. J. M. S. (2004). Análise envoltória de dados. In: Santos, M. L. \& Vieira, W. C. (Eds.). Métodos quantitativos em economia. Viçosa: UFV.

Haynes, E. K. \& Dinc, M. (2005). Data Envelopment Analysis (DEA). In: KEMPFLEONARD, K. (Ed.). Encyclopedia of social measurement. (v. 1). New York: Elsevier, p. 609-616.

Hsu, F. \& Hsueh, C. (2009). Measuring relative efficiency of government-sponsored R\&D projects: a three-stage approach. Evaluation and Program Planning, Oxford, 32 (2), 178-186.

Koopmans, T. C. (1951). Analysis of production as an efficient combination of activities. Nova York: Wiley.

Kozyreff Filho, E. \& Milioni, A. Z. (2004). Um método para estimativa de metas DEA. Revista Produção, São Paulo, 14(2), 270-281.

Lapa, J. S., Belloni, J. A. \& Neiva, C. C. (1997). Medida de desempenho de unidades acadêmicas de uma instituição de ensino superior. Florianópolis: UFSC.

Lapa, J. S. \& Neiva, C. C. (1996). Avaliação em Educação: comentários sobre desempenho e qualidade. Ensaio: avaliação e políticas públicas em educação, Rio de Janeiro, 4(12), 213-236.

Lins, M. P. E. \& Meza, L. A. (2000). Análise envoltória de dados e perspectivas de integração no ambiente de apoio à decisão. Rio de Janeiro: COPPE/UFRJ.

Marconi, M. A. \& Lakatos, E. M. (2007). Metodologia científica: ciência e conhecimento científico, métodos científicos, teoria, hipóteses e variáveis. (5a ed.). São Paulo: Atlas.

Marinho, A. \& Cardoso, S. S. (2007). Avaliação da eficiência técnica e da eficiência de escala do sistema nacional de transplantes. Texto para discussão n. 1260. Rio de Janeiro: IPEA.

Marini, C. \& Martins, H. (2004). Um Governo Matricial: estruturas em rede para geração de resultados de desenvolvimento, IX Congresso Interamericano do Clad sobre a Reforma do Estado e da Administração Pública, Anais..., Madri.

Martos, E. (2013). O conteúdo jurídico do princípio da eficiência no direito financeiro. Dissertação de Mestrado em Direito - Faculdade de Direito, Universidade de São Paulo, São Paulo. 
Mello, J. C. C. B. S., Gomes, E. G., Meza, L. A. \& Mello, M. H. C. S. (2003). Uma análise da qualidade e da produtividade de programas de pós-graduação em Engenharia. Ensaio: avaliação e políticas públicas em educação, Rio de Janeiro, 11 (39), 167-179.

Menezes, E. T. \& Santos, T. H. (2001). Verbete IQCD (Índice de Qualificação do Corpo Docente). Dicionário Interativo da Educação Brasileira - Educabrasil. São Paulo: Midiamix. Recuperado em 08 nov 2019 de https://www.educabrasil.com.br/iqcd-indice-de-qualificacao-do-corpodocentel

Meyer Júnior, V. (1993). A busca da qualidade nas instituições universitárias. Enfoque, Rio de Janeiro, 10 (set), 18-21.

Moreira, N. P. (2018). Análise espacial e temporal da eficiência relativa em universidades federais brasileiras sob a política pública REUNI. Tese de Doutorado em Administração - Universidade Federal de Lavras, Lavras.

Moreno, A.C. (2018). 90\% das Universidades Federais tiveram perda real no orçamento em cinco anos; verba nacional encolheu 28\%. G1 Educação, São Paulo, 29 jun. 2018. Recuperado em 08 nov 2019 de https://g1.globo.com/educacao/noticia/90-das-universidades-federaistiveram-perda-real-no-orcamento-em-cinco-anos-verba-nacional-encolheu28.ghtml

Mueller, S. P. M. \& Perucchi, V. (2014). Universidades e a produção de patentes: tópicos de interesse para o estudioso da informação tecnológica. Perspectivas em Ciência da Informação, Belo Horizonte, 19(2), 15-36.

Neves, D. S. \& Malta; S. C. L. (2014). Ensino, pesquisa e extensão: existem dificuldades docentes no ensino superior para esta integração? Form@re Revista do Plano Nacional de Formação de Professores da Educação Básica. Universidade Federal do Piauí, Teresina, 2(1), 2-12.

Nuintin, A. A. (2014) Eficiência da aplicação de recursos públicos nas Universidades Federais. Tese de Doutorado em Administração - Universidade Federal de Lavras, Lavras.

Oliveira, C. E. M. \& Turrioni, J. B. (2006). Avaliação de desempenho de Instituições Federais de Ensino Superior através da Análise por Envoltória de Dados (DEA). In: ENEGEP, 26., 2006. Anais... Fortaleza, p. 1-8. Recuperado em 08 nov 2017 de http://www.iem.unifei.edu.br/turrioni/congressos/ENEGEP/2006/Avaliacao_d e_desempenho_de_instituicoes_federais_de_ensino_superior_atraves_da_an alise_por_envoltoria_de_dados_(DEA).pdf

Ospina, G. L. (1990). Definição de uma agenda para o ensino superior nos anos 90. In: CRUB. Universidade, Estado e Sociedade na década de 90. Brasília.

Petrucci, V. \& Schwarz, L. (1999). Administração pública gerencial: a reforma gerencial de 1995. Ensaios sobre a reforma administrativa brasileira no limiar do século XXI. Brasília: UnB. 
Pivetta, H. M. F., Backes, D. S., Carpes, A., Battistel, A. L. H. T. \& Marchiori, M. (2010). Ensino, Pesquisa e Extensão Universitária: Em busca de uma integração efetiva. Linhas Críticas, Brasília, 16(31), 377-390.

Revilla, E., Sarkis, J. \& Modrego, A. (2003). Evaluating performance of publicprivate research collaborations. Journal Operational Research Society, Oxford, 54 (2), 165-174.

Santos, B. S. (2004). A universidade no século XXI. São Paulo: Cortez.

Severino, A. J. (2006). A avaliação no PNPG 2005-2010 e a política de pósgraduação no Brasil. In: Ferreira, N. S. C. (Org.). Políticas públicas e gestão da educação: polêmicas, fundamentos e análises. Brasília: Líber Livro, 51-74.

Silva, A. A. P., Ferreira, M. A. M., Braga, M. J. \& Abrantes, L. A. (2012). Eficiência na alocação de recursos públicos destinados à educação, saúde e habitação em municípios mineiros. Contabilidade, gestão e governança, Brasília, 15 (1), 96-114.

Sonje, A.; Deskar-Skrbic, M. \& Sonje, V. (2018). Efficiency of public expenditure on education: comparing Croatia with other nms. INTED2018 CONFERENCE 5th7th March 2018. Proceedings... Valencia, Spain, 2317- 2326.

Tavares, M. G. M., Oliveira, M. A. A. \& Seiffert, O. M. L. B. (2011). Avaliação da educação superior na revista Ensaio: Avaliação e Políticas Públicas em Educação: ênfases e tendências. Ensaio: Avaliação e Políticas Públicas em Educação, Rio de Janeiro, 19 (71), 233-258.

Tribunal de Contas da União. (2006). Orientações para o cálculo dos indicadores de gestão: decisão plenária n 408/2002. Brasília.

Wen-Chih, C., Shu, C. H. \& Chih-Wei, L. (2012). Determine product family mix and priority mix for semiconductor fabrication. European Journal of Operational Research, Amsterdam, 2, 6. 


\section{CONTRIBUIÇÕES DOS AUTORES}

\begin{tabular}{|l|c|c|}
\hline \multicolumn{1}{|c|}{ Contribuição } & $\begin{array}{c}\text { Franciane de } \\
\text { Oliveira } \\
\text { Alvarenga }\end{array}$ & Pierre Ohayon \\
\hline $\begin{array}{l}\text { 1. Idealização e concepção do assunto e tema da } \\
\text { pesquisa }\end{array}$ & $\checkmark$ & $\checkmark$ \\
\hline 2. Definição do problema de pesquisa & $\checkmark$ & \\
\hline 3. Desenvolvimento da Plataforma Teórica & $\checkmark$ & \\
\hline $\begin{array}{l}\text { 4. Delineamento da abordagem metodológica da } \\
\text { pesquisa }\end{array}$ & $\checkmark$ & \\
\hline 5. Coleta de dados & $\checkmark$ & \\
\hline 6. Análises e interpretações dos dados coletados & $\checkmark$ & \\
\hline 7. Conclusões da pesquisa & $\checkmark$ & \\
\hline 8. Revisão crítica do manuscrito & & \\
\hline $\begin{array}{l}\text { 9. Redação final do manuscrito, conforme as normas } \\
\text { estabelecidas pela Revista. }\end{array}$ & $\checkmark$ \\
\hline 10. Orientação & & \\
\hline
\end{tabular}

